\title{
Non-cooperative and Cooperative Game-Theoretic Models for Usage-based Lease Contracts
}

\author{
Maryam Hamidi $^{a}$, Haitao Liao ${ }^{b, 1}$, Ferenc Szidarovszky $^{c}$ \\ ${ }^{a}$ Department of Systems and Industrial Engineering \\ University of Arizona, Tucson, AZ 85721, USA. \\ ${ }^{b}$ Department of Industrial Engineering \\ University of Arkansas, Fayetteville, AR 72701, USA. \\ ${ }^{c}$ Reliasoft Corporation \\ 1450 S. Eastside loop, Tucson, AZ 85710, USA
}

\begin{abstract}
In this paper, we study game-theoretic models for lease contracts, by which the owner (lessor) rents a piece of equipment to a user (lessee). The lessee decides on the optimal lease period and usage rate, and the lessor is responsible for developing a maintenance policy for the equipment. Two non-cooperative game-theoretic models and a cooperative model are developed to describe the relationships between the two decision makers. In the non-cooperative simultaneous move game, the lessee and the lessor act simultaneously and independently to make their decisions. In the leader-follower non-cooperative game, the lessor is the leader who specifies the maintenance policy first, and the lessee, as the follower, decides on the lease period and usage rate accordingly. For these two games, the Nash and Stackelberg equilibria are obtained respectively. For the cooperative game, we derive the solution targeting on total profit maximization and show that this solution can be implemented as an equilibrium using a nonlinear transfer-payment contract. Besides, we compare the Nash equilibrium, Stackelberg equilibrium, and the total maximum solution to each other, and our results show that the lessee and lessor can gain more profit from the cooperative contract than from the non-cooperative alternatives. Numerical examples are provided to demonstrate the different solution methodologies and the value of cooperation.
\end{abstract}

\footnotetext{
${ }^{1}$ Corresponding author. Tel.: 1 (479) 575-6196; fax: 1 (479) 575-8431

E-mail addresses: mhamidi@email.arizona.edu (M. Hamidi), liao@uark.edu (H. Liao), Ferenc.Szidarovszky@reliasoft.com (F. Szidarovszky)
} 
Keywords: Lease contracts; Game theory; Usage rate; Maintenance; Coordination mechanism

\section{Introduction}

Equipment leasing is a process by which the owner (lessor) rents a piece of equipment to a user (lessee) under a lease contract. It is increasingly common for companies to lease equipment rather than to own it (Jaturonnatee et al., 2006). Over $80 \%$ of American businesses lease at least one of their equipment acquisitions, and nearly $90 \%$ say they would choose to lease again (Giddy, 2004). Part of the motivations are saving on initial investment, flexibility on equipment upgrading, and cost reduction in maintenance and inventory. In this paper, we study a lease contracting problem where the lessee decides on the optimal lease period and usage rate and the lessor is responsible for developing a maintenance policy for the equipment.

Many studies on leased equipment deterioration are focused only on the effect of age (time) while ignoring the effect of actual usage. In reality, however, many lease contracts are characterized by both the lease period (time) and the usage. A typical example is an automobile leased for 3 years and up to 10,000 miles per year. Other examples of usage include the number of pages produced by a photocopier, the flight hours operated by aircraft (Jack et al., 2009), and the weight carried by a mining haul truck. Although extensive research has been done on warranty policies considering both time and usage (Kim \& Rao, 2000; Chen \& Popova, 2002; Iskandar et al., 2005; Jack et al., 2009; Shafiee \& Chukova, 2013), they have received little attention in decision making of lease contracts. In this paper, the effects of both time and usage on deterioration of leased equipment are considered.

In practice, preventive maintenance (PM) is usually performed by the lessor to achieve a trade-off between the failure cost and the PM cost. In the literature, PM policies considering imperfect maintenance of leased equipment have been studied. Jaturonnatee et al. (2006) derived the optimal number of PM actions to be carried out during the lease period along with the time and the degree of each PM action. Conceptually, the degree of PM quantifies the reduction in the equipment's failure intensity. Yeh et al. (2009) considered a problem assuming a fixed degree for all maintenance actions. Pongpech \& Murthy (2006) determined the degree of each action under a periodic maintenance policy. Chang \& Lo (2011) studied a case where PM actions were carried out when the equipment's failure intensity reached a specified level. In this paper, we assume that the lessor will perform periodic PM (Yeh \& Chen, 2006) with a fixed degree for all actions. Such PM 
actions not only reduce the number of failures during the lease period but also increase the residual value of the equipment by the time when the lease contract expires. Besides, we consider that the productivity of the leased equipment decreases as it deteriorates, so PM actions also reduce the revenue loss caused by deterioration (Wu et al., 2011).

A lease contract should be an instruction that is satisfactory to both lessor and lessee (Wang et al., 2015). To this end, developing a framework to address their individual perspectives is crucial (Murthy \& Jack, 2014). One of the most popular approaches in dealing with such problems is game theory. Depending on the behavior of the decision makers (players), game-theoretic models can be classified into non-cooperative and cooperative games. In a non-cooperative formulation, players decide independently. Nash (Dong et al., 2004) and Stackelberg equilibria (Esmaeili et al., 2009) are the two most popular solution concepts used in these games, both of which are based on the analysis of best response functions. When the players choose their strategies simultaneously, Nash equilibrium applies, but when one player decides before the other, the Stackelberg solution is appropriate. The advantage of contracting based on these equilibrium solutions is that no player has a temptation to deviate from the agreement to increase his profit (Chiu et al., 2014). However, these contracts are not efficient since they do not maximize the total profit of the players (Cachon, 2003). A possible solution is for the decision makers to cooperate when determining the terms of contract (Matsumoto \& Szidarovszky, 2016; Giannoccaro \& Pontrandolfo, 2004; Leng \& Parlar, 2005), so that an outcome better than the Nash or Stackelberg equilibria (Nagarajan \& Sošić, 2008; Kim \& Ha, 2003) can be achieved. Esmaeili et al. (2014) presented three-level warranty service contracts among manufacturer, agent, and customer. Under different game-theoretic games, they determined the optimal sale price, warranty period, and warranty price for the manufacturer and the optimal maintenance cost for the agent by maximizing their profits.

In this paper, we study three lease contract models based on non-cooperative and cooperative games. For the non-cooperative games, two scenarios are considered: noncooperative simultaneous move game and non-cooperative leader-follower game. In the first scenario, the lessee and lessor choose their strategies simultaneously while, in the second scenario, the lessor dominates the lessee by determining his maintenance policy first, and then the lessee chooses the lease period and usage rate. We respectively derive the Nash and Stackelberg equilibria and compare the corresponding strategies and payoffs. Next, for the cooperative game model, we derive the solution targeting on total profit maximization. It is of interest to compare the performance of the non-cooperative contracts and the cooperative alternative. One measure of performance is the difference between the total profit of a non-cooperative contract and that of a cooperative one (which 
has the maximum total profit). By comparing the total profits, we will demonstrate the conditions under which the non-cooperative lease contracts have a poor performance, and thus the lessee and lessor can gain much more profits by switching to the cooperative alternative.

It is worth pointing out that implementation of the cooperative solution requires two major criteria. First, cooperation should lead to a win-win situation for the lessee and lessor (Tarakci et al., 2006), such that the profits of both players become higher compared to the non-cooperative cases. Second, the players should have no incentive to deviate from the cooperative solution, i.e., they should modify their profits such that the total maximum solution becomes identical to a Nash equilibrium (for the simultaneous move case) and a Stackelberg equilibrium (for the leader-follower case) (Cachon \& Zipkin, 1999). We will show that these two criteria can be achieved by a nonlinear transfer-payment contract. We have allocated the maximum total profit between the players based on Nash bargaining solution to satisfy the first criterion. The related literature has overwhelmingly showed cases where decision makers negotiate over different contract terms (Nagarajan \& Sošić, 2008). Gurnani \& Shi (2006) and Nagarajan \& Sošić (2008) provided reviews of such contracts. Bajari et al. (2009) analyzed a comprehensive data set of building construction contracts and observed that almost half of the contracts were developed through negotiation. The study suggested that more complicated projects were more likely to be negotiated. Similar approaches have been considered in distribution channels, franchising arrangements, and inventory control systems (Chen et al., 2001; Nagarajan \& Bassok, 2008; Leng \& Zhu, 2009; Leng \& Parlar, 2010).

The remainder of this paper is organized as follows. The mathematical formulations for equipment failure intensity, maintenance costs, revenue, residual value, as well as the lessee's and the lessor's payoff functions are given in Section 2. The non-cooperative solution methodologies are described in Section 3, where the best response functions of lessee and lessor are derived, the Nash and Stackelberg equilibria are determined, and the corresponding strategies and payoffs are compared. Section 4 analyzes the cooperative game solution and compares it with the non-cooperative solutions. Next, a nonlinear transfer-payment function is introduced to implement the cooperative solution. Section 5 presents numerical examples to illustrate the three lease contract models and to investigate their performance. Finally, Section 6 concludes the paper. 


\section{Problem Description and Model Formulation}

It is assumed that the new equipment to be leased has life cycle $L$, and its maximum usage rate is $r_{m}$ (Iskandar et al., 2005; Jack et al., 2009) which is the maximum allowable capacity per unit of time (e.g., 20,000 miles per year for a leased car or 240 tons per day for a mining haul truck). The lessee leases the equipment at a usage rate $r\left(\leq r_{m}\right)$ for a certain period $K$ and pays the lessor an annual payment based on the usage rate. During the lease period, the lessor will perform periodic PM for $N$ times each with degree $\delta$ which to be specified in the contract. The vale of $\delta$ is between 0 (perfect maintenance) and 1 (minimum repair). In addition, the lessor will do minimal repair (i.e., corrective maintenance (CM) that does not change the equipment's failure intensity) to fix any failure that occurs within the lease period. The equipment generates revenue $Y(r, K, N, \delta)$ for the lessee during the lease period, and it has residual value $S V(r, K, N, \delta)$ for the lessor at the end of the lease period.

In this paper, the lease contracts are modeled in a two-person game-theoretic framework. Specifically, the decision variables of the lessee are $K$ and $r$, and his strategy $\mathbf{x}_{1}=(r, K)$ belongs to the following strategy set:

$$
X_{1}=\left\{(r, K) \mid 0 \leq r \leq r_{m}, 0 \leq K \leq L\right\}
$$

where we specify that the lease period $K$ should not exceed the equipment's life cycle $L$. On the other hand, the lessor's strategy $\mathbf{x}_{2}=(N, \delta)$ is within the strategy set $X_{2}$ :

$$
X_{2}=\{(N, \delta) \mid N \geq 0 \text { integer, } 0 \leq \delta \leq 1\}
$$

In addition to the decision strategies, the players' objective functions (payoff functions) need to be determined. Next, we will formulate the payoff functions of the lessee and the lessor by first introducing the related terms.

\subsection{Failure Intensity Function}

The leased equipment deteriorates according to a known failure intensity function $\lambda_{0}(r, t)$ which is an increasing function of both usage rate and age. To model the failure intensity, we use one-dimensional point process which treats the usage as a function of age (Chen \& Popova, 2002; Iskandar \& Murthy, 2003; Iskandar et al., 2005). Let $T(t)$ be the equipment's cumulative operating time up to time $t$ and $Z(t)$ be the total usage. For simplicity, we assume that the equipment's operating time equals its age, i.e., $T(t)=t$. This is true if all failures in $(0, t)$ are repaired, and the repair time is negligible compared 
to the operating time (Iskandar et al., 2005). In practice also calendar time is widely used as the operating time of leased equipment (Huang \& Yen, 2009). Besides, we consider a constant usage rate $r$ such that $Z(t)=r t$. Based on these assumptions, linear, log-linear, and power intensity functions reduce to:

$$
\begin{gathered}
\lambda_{0}(t)=\theta_{1} Z(t)+\theta_{2} T(t)=t\left(\theta_{1} r+\theta_{2}\right) \\
\lambda_{0}(t)=\exp \left(\theta_{1} Z(t)+\theta_{2} T(t)\right)=\exp \left(\theta_{1} r t+\theta_{2} t\right) \\
\lambda_{0}(t)=\theta_{0} Z(t)^{\theta_{1}} T(t)^{\theta_{2}}=\theta_{0} r^{\theta_{1}} t^{\theta_{1}+\theta_{2}}
\end{gathered}
$$

with parameters $\theta_{i} \geq 0$ for $i=0,1,2$ (see Iskandar et al. (2005) for other models). It can be easily seen that model (3) is in the form of a Weibull intensity function, $\lambda_{0}(t)=\alpha \beta(\alpha t)^{\beta-1}$, with shape parameter $\beta=2$ and scale parameter $\alpha=\sqrt{\frac{\theta_{1} r+\theta_{2}}{2}}$ that is a function of usage rate $r$; model (4) describes a Gumbel intensity function, $\lambda_{0}(t)=\frac{e^{(t-\mu) / \sigma}}{\sigma}$ with $\mu=\frac{\ln \left(\theta_{1} r+\theta_{2}\right)}{\theta_{1} r+\theta_{2}}$ and $\sigma=1 /\left(\theta_{1} r+\theta_{2}\right)$, and model (5) is also a Weibull intensity function with $\alpha=\left(\frac{\theta_{0} r^{\theta_{1}}}{\theta_{1}+\theta_{2}+1}\right)^{1 /\left(\theta_{1}+\theta_{2}+1\right)}$ and $\beta=\theta_{1}+\theta_{2}+1>1$. Without loss of generality, model (3) is considered in this paper, and the optimal values of usage rate $r$ and lease period $K$ will be determined and compared based on the three different lease contract models. The other intensity functions can be used in an analogous manner.

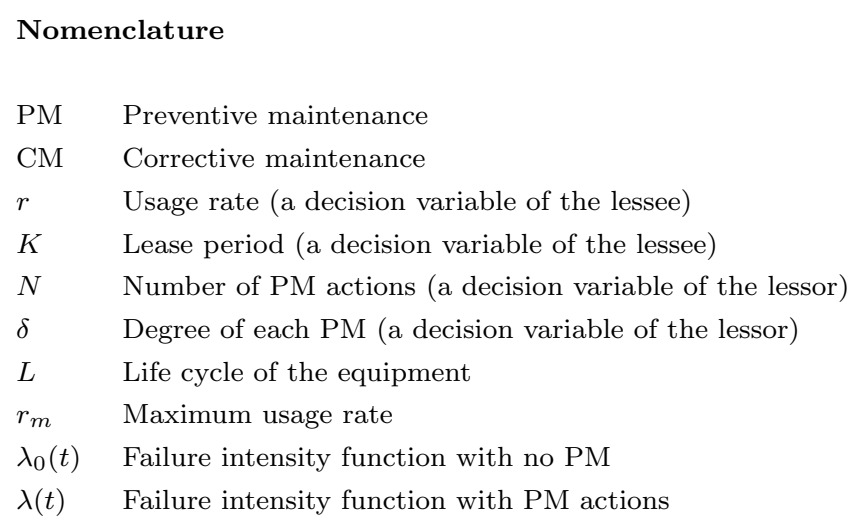

$\lambda(t) \quad$ Failure intensity function with PM actions

$\begin{array}{ll}H(\mathbf{x}) & \text { Nonlinear transfer function } \\ \gamma, \bar{\alpha}_{0}, \beta & \text { Side-payment contract parameters } \\ \Pi_{1} & \text { Lessee's payoff } \\ \Pi_{2} & \text { Lessor's payoff } \\ \bar{\Pi}_{1} & \text { Lessee's payoff with transfer payment } \\ \bar{\Pi}_{2} & \text { Lessor's payoff with transfer payment } \\ \Pi & \text { Total payoffs of lessee and lessor } \\ \mathbf{x}_{n}^{*} & \text { Nash equilibrium } \\ \mathbf{x}_{s}^{*} & \text { Stackelberg equilibrium } \\ \mathbf{x}_{c}^{*} & \text { Total maximum solution (cooperative) }\end{array}$

\subsection{Preventive Maintenance and Cost}

The lessor will perform periodic PM at time epochs $\tau, 2 \tau, \ldots, N \tau$, where $\tau=\frac{K}{N+1}$ is the constant time interval between two successive PM actions (Pongpech \& Murthy, 2006; Yeh \& Chen, 2006; Chang \& Lo, 2011). The effect of PM can be formulated by age reduction models which assume that PM reduces the age of a maintained item to a younger age 
(Levitin \& Lisnianski, 2000; Kim \& Ha, 2003; Kahle, 2007; Bartholomew-Biggs et al., 2009; Yeh et al., 2011). In this paper, we use Kijima type-I age reduction model (Kijima, 1989) where PM reduces the equipment's age from $t$ to a virtual age $\nu(t)<t$.

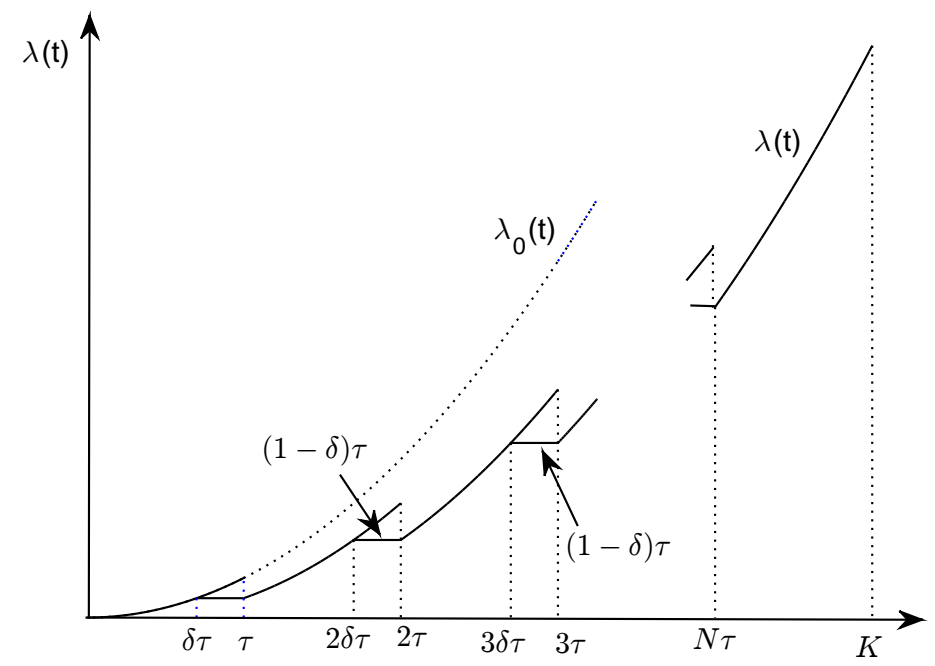

Fig. 1. Failure intensity function under PM actions

We assume all periodic PM actions have the same degree $0 \leq \delta \leq 1$. As shown in Fig. 1, the failure intensity function without PM is $\lambda_{0}(t)$, and after performing PM, the failure intensity function is reduced to $\lambda(t)$ where $\lambda(t)<\lambda_{0}(t)$. According to Kijima type-I model, the virtual age of the equipment immediately after performing PM at time epoch $i \tau$ is $\nu_{i}=i \delta \tau$ for $i=0,1, \ldots, N$, meaning that PM reduces the equipment's total age by $(1-\delta) \tau$ at each time epoch. As a result, the equipment's virtual age between the $i^{\text {th }}$ and $(i+1)^{s t} \mathrm{PM}$ actions can be expressed as:

$$
\nu(t)=i \delta \tau+t-i \tau, \quad \text { for } i \tau \leq t<(i+1) \tau
$$

Replacing the equipment's age $t$ in (3) by its virtual age $\nu(t)$, the failure intensity function with PM can be expressed as:

$$
\lambda(t)=\lambda_{0}(\nu(t))=\nu(t)\left(\theta_{1} r+\theta_{2}\right)=(i \delta \tau+t-i \tau)\left(\theta_{1} r+\theta_{2}\right)
$$

It is reasonable to assume that the cost of a PM action is a nonnegative and nondecreasing function of age reduction $(1-\delta) \tau$. In particular, we consider a linear function for the cost of each PM action, i.e., $C_{p}=a+b(1-\delta) \tau$. As a result, the total cost of PM actions during the lease period $K=(N+1) \tau$ is given by:

$$
C_{p}=N a+\frac{N b K(1-\delta)}{(N+1)}
$$


where $a, b>0$ (Pongpech \& Murthy, 2006; Jaturonnatee et al., 2006; Yeh et al., 2011). In the latter part of the paper, the optimal values of $N$ and $\delta$ for the three different contract lease models will be determined and compared.

\subsection{Corrective Maintenance and Cost}

During the lease period, any failure of the leased equipment is minimally repaired by the lessor. Such minimal repairs make the equipment operational but keep the failure intensity the same as that just before the failure. Assuming each minimal repair incurs a fixed cost $C_{f}$, the expected total repair cost depends on the expected number of failures during the lease period.

Without performing any PM actions, the failure process of the leased equipment is Non-homogeneous Poisson Process (NHPP) with failure intensity $\lambda_{0}(t)$ (Jaturonnatee et al., 2006; Chang \& Lo, 2011). When PM is considered, the failure process of the equipment in each interval $[i \tau,(i+1) \tau)$ for $i=0,1, \ldots, N$ is still an NHPP with intensity function $\lambda(t)=\lambda_{0}(\nu(t))$, meaning that failures happen according to the virtual age of the equipment (Kim et al., 2004). As a result, the total expected number of failures with PM over the lease period is:

$$
\begin{aligned}
\sum_{i=0}^{N} \int_{i \tau}^{(i+1) \tau} \lambda_{0}(\nu(t)) d t & =\sum_{i=0}^{N} \int_{i \tau}^{(i+1) \tau}(i \delta \tau+t-i \tau)\left(\theta_{1} r+\theta_{2}\right) d t \\
& =\frac{K^{2}\left(\theta_{1} r+\theta_{2}\right)(N \delta+1)}{2(N+1)}
\end{aligned}
$$

Combining (9) with the cost of each $\mathrm{CM}, C_{f}$, the total cost of $\mathrm{CM}$ is given by:

$$
C_{m}=\frac{C_{f} K^{2}\left(\theta_{1} r+\theta_{2}\right)(N \delta+1)}{2(N+1)}
$$

\subsection{Lessee's Revenue by Using the Equipment}

Ideally, a higher usage rate results in higher revenue per unit of time. In reality, however, the efficiency of equipment decreases because of aging and usage. Essentially, deterioration causes revenue loss (Wu et al., 2011) due to reduced speed, poor product quality, and increased operating costs such as fuel consumption (Al-Najjar \& Alsyouf, 2004; Marais \& Saleh, 2009). Let $u_{m}$ be the potential revenue per unit of time that can be generated by the new equipment if its capacity is fully used (i.e., $u\left(t=0 ; r=r_{m}\right)$ ) (Wu et al., 2011). Also assume that the revenue rate at the end of the equipment's life cycle is zero, i.e., $u(t=L, r)=0$. Similar to the Cobb-Douglas production function, the revenue rate can 
be formulated as the product of an increasing function in $r$ and a decreasing function in $t$ as:

$$
u_{0}(r, t)=\frac{u_{m}}{r_{m}} r\left(1-\frac{t}{L}\right)
$$

Because PM makes the equipment younger, it slows down the revenue loss caused by deterioration. By substituting time $t$ with the equipment's virtual age $\nu(t)$ in model (11), the total revenue generated for the entire lease period $K$ can be expressed as:

$$
\begin{aligned}
Y(r, K, N, \delta) & =\sum_{i=0}^{N} \int_{i \tau}^{(i+1) \tau} u_{0}(r, \nu(t)) d t=\sum_{i=0}^{N} \int_{i \tau}^{(i+1) \tau} \frac{u_{m}}{r_{m}} r\left(1-\frac{i \delta \tau+t-i \tau}{L}\right) d t \\
& =\frac{u_{m}}{r_{m}} \frac{r K}{L}\left[L-\frac{K(1+\delta N)}{2(N+1)}\right]
\end{aligned}
$$

\subsection{Residual Value of the Equipment}

The residual value of the leased equipment at the end of the lease period $(K)$ is a critical factor in setting lease terms. Monga \& Zuo (2001) proposed that the equipment's residual value can be modeled as a function of its failure intensity. Chang \& Lo (2011) considered the residual value as a linearly decreasing function of time. In this paper, we consider both the total usage and age (e.g., the residual value of a car largely depends on its mileage and age) in modeling the equipment's residual value:

$$
S V_{0}(r, t)=\theta_{5}-\theta_{3} X^{2}(t)-\theta_{4} T^{2}(t)
$$

with $\theta_{3}, \theta_{4}, \theta_{5} \geq 0$. It is worth pointing out that PM increases the equipment's residual value. By substituting the virtual age $\nu(K)$ into (13), the residual value with PM at the end of the lease period $K$ becomes:

$$
S V(r, K, N, \delta)=S V_{0}(r, \nu(K))=\theta_{5}-\frac{\left(\theta_{3} r^{2}+\theta_{4}\right)(N \delta+1)^{2} K^{2}}{(N+1)^{2}}
$$

We also assume that the equipment's purchase price is $S V(0,0)=V_{0}$, and at the end of the life cycle $L$ when it is used at the maximum usage rate, it has residual value $S V\left(r_{m}, L\right)=V_{L}$. As a result, we have $\theta_{5}=V_{0}$ and $\theta_{4}=\frac{V_{0}-V_{L}}{L^{2}}-\theta_{3} r_{m}^{2}$.

\subsection{Payoff Functions of the Lessee and Lessor}

The payoff of the lessee is defined as the total profit he gains by using the equipment. In particular, his total profit, denoted by $\Pi_{1}(r, K, N, \delta)$, can be calculated considering the revenue generated by the equipment (12) and the total price paid for leasing as:

$$
\Pi_{1}(r, K, N, \delta)=\frac{u_{m} r K}{r_{m} L}\left[L-\frac{K(N \delta+1)}{2(N+1)}\right]-\alpha_{0} r^{2} K
$$


On the other hand, the total profit of the lessor is defined as the price the lessee pays for leasing, minus the costs of performing PM (8) and CM (10), and the equipment depreciation (14). As a result, the lessor's profit can be expressed as:

$$
\begin{aligned}
\Pi_{2}(r, K, N, \delta)= & \alpha_{0} r^{2} K-N a-\frac{N b K(1-\delta)}{(N+1)}-\frac{K^{2} C_{f}\left(\theta_{1} r+\theta_{2}\right)(N \delta+1)}{2(N+1)} \\
& -\frac{K^{2}\left(\theta_{3} r^{2}+\theta_{4}\right)(N \delta+1)^{2}}{(N+1)^{2}}
\end{aligned}
$$

\section{Non-cooperative Solutions}

We first consider that the lessor and lessee compete in a non-cooperative fashion, and the governing optimization/equilibrium concept underlying non-cooperative behavior is that of Nash. A pair of strategies is a Nash equilibrium if no single player can obtain a higher payoff by deviating unilaterally from his strategy (Osborne \& Rubinstein, 1994; Matsumoto \& Szidarovszky, 2016). We next consider Stackelberg equilibrium with lessor as the leader. The Stackelberg version represents a situation where the lessor is dominant in the game. The usual way to find Nash and Stackelberg equilibria is based on the players' best response functions.

The best response function in a two-person game can be described as follows. Suppose $\Pi_{1}\left(\mathbf{x}_{1}, \mathbf{x}_{2}\right)$ and $\Pi_{2}\left(\mathbf{x}_{1}, \mathbf{x}_{2}\right)$ are the payoff functions of players 1 and 2 when they choose $\mathbf{x}_{1} \in X_{1}$ and $\mathbf{x}_{2} \in X_{2}$ from their respective strategy sets. We call the strategy of player 1 , denoted by $x_{1 R}^{*}\left(\hat{\mathbf{x}}_{2}\right)$, which maximizes his payoff given that player 2's strategy is $\hat{\mathbf{x}}_{2}$, the best response of player 1 to $\hat{\mathbf{x}}_{2}$. The best response function of player $2, x_{2 R}^{*}\left(\mathbf{x}_{1}\right)$, as function of $\mathbf{x}_{1}$, can be defined in the same manner. In this section, the best response functions of the lessee and lessor will be determined (Sections 3.1 and 3.2), and the Nash and Stackelberg non-cooperative game models will be developed (Sections 3.3 and 3.4) and compared (Sections 3.5).

\subsection{Lessee's Best Response Function}

The best response function of the lessee can be determined by solving the following problem:

$$
\begin{array}{ll}
\max _{r, K} & \Pi_{1}(r, K)=\frac{u_{m} r K}{r_{m} L}\left[L-\frac{K(N \delta+1)}{2(N+1)}\right]-\alpha_{0} r^{2} K \\
\text { s.t. } & 0 \leq r \leq r_{m} \\
& 0 \leq K \leq L
\end{array}
$$


In the problem formulation, the lessee seeks to maximize his profit based on his strategy set in $(1)$, while taking the lessor's strategies $(N, \delta)$ as given. Setting the first derivative of $\Pi_{1}(r, K)$ with respect to $r$ equal to zero and solving for $r$ yields:

$$
r_{1}^{*}(K)=\frac{u_{m}}{2 \alpha_{0} r_{m} L}\left[L-\frac{K(N \delta+1)}{2(N+1)}\right]
$$

Similarly, setting the first derivative of $\Pi_{1}(r, K)$ with respect to $K$ equal to zero and solving for $K$ yields:

$$
K_{1}^{*}(r)=\frac{(N+1)}{(N \delta+1)}\left[L-\frac{\alpha_{0} r_{m} L r}{u_{m}}\right]
$$

Accordingly, solving the problem in (17) gives the optimality conditions for the lessor and lessee, as presented in Proposition 1 (see Appendix for the proof).

Proposition 1. The lessee's best response in terms of usage rate and lease period $(r, K)$ is:

i. $\left(r_{1}^{*}(L), L\right)$ when $A_{1}>0, D_{1}<0$

ii. $\left(r_{m}, L\right)$ when $C_{1}>0, D_{1}>0$

iii. $\left(r_{m}, K_{1}^{*}\left(r_{m}\right)\right)$ when $B_{1}>0, C_{1}<0$

iv. $\left(\bar{r}_{1}, \bar{K}_{1}\right)$ when $A_{1}<0, B_{1}<0$

where $\left(\bar{r}_{1}, \bar{K}_{1}\right)$ is the solution to (18) - (19) as $\left(\bar{r}_{1}=\frac{u_{m}}{3 \alpha_{0} r_{m}}, \bar{K}_{1}=\frac{2 L(N+1)}{3(N \delta+1)}\right)$, and $A_{1}=$ $2 N-3 N \delta-1, B_{1}=u_{m}-3 \alpha_{0} r_{m}^{2}, C_{1}=u_{m}(N-N \delta)-(N+1) \alpha_{0} r_{m}^{2}$, and $D_{1}=$ $u_{m}(2 N-N \delta+1)-4(N+1) \alpha_{0} r_{m}^{2}$.

It is worth pointing out that for any given preventive maintenance policy $(N, \delta)$ of the lessor, this proposition gives strategies $(r, K)$ that maximize lessee's payoff.

\subsection{Lessor's Best Response Function}

The best response function of the lessor can be derived by solving the following problem:

$$
\begin{array}{ll}
\max _{N, \delta} & \alpha_{0} r^{2} K-N a-\frac{2 N b K(1-\delta)+K^{2} C_{f}\left(\theta_{1} r+\theta_{2}\right)(N \delta+1)}{2(N+1)}-\frac{K^{2}\left(\theta_{3} r^{2}+\theta_{4}\right)(N \delta+1)^{2}}{(N+1)^{2}} \\
\text { s.t. } & 0 \leq \delta \leq 1 \\
& N=0,1, \ldots
\end{array}
$$

In the problem formulation, the lessor seeks to maximize his profit $\Pi_{2}$ subject to two sets of constraints in (2), while taking the lessee's strategies $(r, K)$ as given. The first order 
derivative of the objective function with respect to $N$ is:

$$
\Pi_{2 N}^{\prime}=-a-\frac{2 b K(1-\delta)-K^{2} C_{f}\left(\theta_{1} r+\theta_{2}\right)(1-\delta)}{2(N+1)^{2}}+\frac{2 K^{2}\left(\theta_{3} r^{2}+\theta_{4}\right)(N \delta+1)(1-\delta)}{(N+1)^{3}}
$$

Setting this expression equal to zero and solving for $N$ leads to a cubic equation whose solution $N_{2}^{*}$ can be determined in closed form using the Cardano formula. The unique maximum $N_{2}^{*}$ is given by (see Proposition 2 and the proof in Appendix):

$$
N_{2}^{*}=\frac{1}{3 a}\left(C_{2}+\frac{3 a B_{2}}{C_{2}}\right)-1
$$

where $B_{2}=\frac{K^{2}}{2} C_{f}\left(\theta_{1} r+\theta_{2}\right)-b K, C_{2}=\sqrt[3]{\frac{54 a^{2} K^{2}\left(\theta_{3} r^{2}+\theta_{4}\right)+\sqrt{-27 a^{2} Q_{2}}}{2}}$, and $Q_{2}=4 a B_{2}^{3}-$ $108 a^{2} K^{4}\left(\theta_{3} r^{2}+\theta_{4}\right)^{2}$.

Proposition 2. $N_{2}^{*}$ is the unique maximum.

Accordingly, the following proposition characterizes the best response function of the lessor (see Appendix for the proof).

Proposition 3. The lessor's best response in terms of maintenance policy $(N, \delta)$ is $\left(N_{2}^{*}, 0\right)$.

This proposition gives the strategies $(N, \delta)$ which maximize the lessor's payoff for any given strategies $(r, K)$ of the lessee. It can be seen that $N$, the optimal number of $\mathrm{PM}$, depends on the strategies the lessee might pick $(r$ and $K$ ), while $\delta=0$ (perfect maintenance) is the lessor's best response to any lease period and usage rate (dominant strategy). It should be noted that in solving the problem we treated $N$ as a continues variable. After solving the problem, if $N_{2}^{*}$ is not an integer, we choose either $\left\lfloor N_{2}^{*}\right\rfloor$ (the largest integer not greater than $N_{2}^{*}$ ) or $\left\lceil N_{2}^{*}\right\rceil$ (the smallest integer not less than $N_{2}^{*}$ ), whichever yields a larger payoff value.

\subsection{The Nash Equilibrium}

In a Nash equilibrium, the best response functions of both players are satisfied. Accordingly, the following theorem provides the Nash equilibrium and the corresponding conditions (see Appendix for the proof).

Theorem 1. The Nash equilibrium $\mathbf{x}_{n}^{*}=\left(r_{n}^{*}, K_{n}^{*}, N_{n}^{*}, \delta_{n}^{*}\right)$ is given by:

i. $\left(r_{1}^{*}, L, N_{3}^{*}, 0\right)$ if $D_{1}<0$

ii. $\left(r_{m}, L, N_{2}^{*}, 0\right)$ if $C_{1}>0, D_{1}>0$ 
It can be seen that the lease period and degree of each PM action are constant $K_{n}^{*}=L$ and $\delta_{n}^{*}=0$ (perfect maintenance), but the usage rate $r_{n}^{*}$ and the number of PM $N_{n}^{*}$ are functions of other strategies. Besides, it should be noted that in case $i i ., N_{2}^{*}$ can be obtained from equation (22), and in case $i ., N_{3}^{*}$ can be obtained by simultaneously solving the two first order conditions for the lessor and the lessee in (18) and (21). This can be calculated by rounding the solution of equation $M_{3}(N)=0$ where:

$$
\begin{gathered}
M_{3}(N)=-a(N+1)^{5}- \\
b L(N+1)^{3}+\frac{L^{2} C_{f}(N+1)^{2}(2 N+1) u_{m}}{8 \alpha_{0} r_{m}}+\frac{L^{2} C_{f} \theta_{2}(N+1)^{3}}{2} \\
+\frac{L^{2} \theta_{3} u_{m}^{2}(2 N+1)^{2}}{8 \alpha_{0}^{2} r_{m}^{2}}+2 L^{2} \theta_{4}(N+1)^{2}
\end{gathered}
$$

In case of multiple solutions, the one with the largest payoff value is selected.

\subsection{The Stackelberg Equilibrium}

In a Stackelberg game, the lessor commits himself to a particular maintenance policy and announces his choice to the lessee. The lessee as the follower then chooses the best lease period and usage rate accordingly. The lessor maximizes his profit by specifying the maintenance policy taking into account the expected behavior of the lessee. Assuming a rational player, the lessor expects the lessee to select his best response. Substituting the best response of the lessee (see Proposition 1) into the lessor's payoff function transforms $\Pi_{2}$ into a nonlinear function of two variables $N$ and $\delta$, whose optimal solution is specified in the following theorem (see Appendix for the proof).

Theorem 2. The Stackelberg equilibrium $\mathbf{x}_{s}^{*}=\left(r_{s}^{*}, K_{s}^{*}, N_{s}^{*}, \delta_{s}^{*}\right)$ is given by:

i. $\left(r_{1}^{*}, L, N_{4}^{*}, 0\right)$ when $D_{1}<0$

ii. $\left(r_{m}, L, N_{2}^{*}, 0\right)$ when $C_{1}>0, D_{1}>0$

iii. $\left(r_{m}, K_{1}^{*}\left(r_{m}\right), 0,1\right)$ when $B_{1}>0, C_{1}<0, M_{1}>0$

iv. $\left(\bar{r}_{1}, \bar{K}_{1}, 0,1\right)$ when $A_{1}<0, B_{1}<0, M_{1}>0$

where

$$
M_{1}=-\alpha_{0} r^{2}+b+\frac{A_{3} C_{f}\left(\theta_{1} r+\theta_{2}\right)}{2}
$$

and $A_{3}=L-\frac{\alpha_{0} r_{m} L r}{u_{m}}$. It should be noted that in cases $i i$, $i i i$, and $i v$, the equilibria are given directly; but in case $i$ equation $M_{4}(N)=0$ needs to be solved for $N$, where:

$$
M_{4}(N)=-a(N+1)^{5}+(N+1)^{3}\left(-b L+\frac{L^{2} C_{f} \theta_{2}}{2}\right)+(N+1)^{2}(2 N+1)\left(\frac{L^{2} C_{f} u_{m} r_{m}+L u_{m}^{2}}{8 \alpha_{0} r_{m}^{2}}\right)
$$




$$
+\frac{L^{2} \theta_{3} u_{m}^{2}(2 N+1)^{2}}{8 \alpha_{0}^{2} r_{m}^{2}}+(N+1)^{2}\left(2 L^{2} \theta_{4}-\frac{L^{2} C_{f} \theta_{1} u_{m}}{8 \alpha_{0} r_{m}}\right)-\frac{L^{2} \theta_{3} u_{m}^{2}(2 N+1)}{8 \alpha_{0}^{2} r_{m}^{2}}
$$

This is a fifth degree polynomial equation possibly with multiple solutions. In case of multiple solutions, the one with the largest payoff value is selected.

\subsection{Comparison of the Nash and Stackelberg Equilibria}

In this section, we compare the two cases of the Nash equilibrium stated in Theorem 1 with the corresponding cases of the Stackelberg equilibrium stated in Theorem 2 ( $i$ and ii). One can see that the lease period $K=L$ (life cycle of the equipment) and the degree of each PM action $\delta=0$ (perfect maintenance) are the same for both games. We need to compare $N$, the number of $\mathrm{PM}$, and $r$, the usage rate, as a function of $N$, but no general results can be proved because of the possible multiple solutions. However, in case of unique solutions it is possible to perform comparison and obtain the following results (see Appendix for the proofs).

Proposition 4. One can see that:

i. When $D_{1}<0$, the number of $P M$ is higher in the simultaneous game (i.e., $N_{3}^{*}>N_{4}^{*}$ ) if $M_{2}(0)<0$ and $\Pi_{2 N}^{\prime}\left(r_{1}^{*}, L, N_{A}, 0\right)<0$, and otherwise it is smaller.

ii. When $C_{1}>0$ and $D_{1}>0$, the number of PM in the simultaneous game is the same as in the Stackelberg game $\left(N_{2}^{*}\right)$.

where $\Pi_{2 N}^{\prime}$ is defined in (21), and $N_{A}$ is the finite unique solution to:

$$
M_{2}(N)=2 \alpha_{0} r_{1}^{*} L-\frac{L^{2} C_{f} \theta_{1}}{2(N+1)}-\frac{2 L^{2} \theta_{3} r_{1}^{*}}{(N+1)^{2}}=0
$$

It is worth pointing out that the same results apply to the comparison of usage rates in both games, as $r_{1}^{*}$ is an increasing function of $N$. Next, we compare the payoffs of these games.

Proposition 5. One can see that:

i. The lessor always prefers the leader-follower structure rather than the simultaneous move structure.

ii. The lessee prefers the game with a higher number of PM.

The first statement is true because the lessor can get at least the payoff of simultaneous move by choosing the Nash equilibrium. For the second statement, one can see that the lessee's payoff is increasing in $N$, so the number of PM determines the lessee's preference (see Proposition 4 regarding the number of PM). 


\section{Cooperative Solution}

In the previous section, we focused on the results for both the non-cooperative simultaneous move game and the leader-follower game, but the corresponding Nash and Stackelberg equilibria generally do not lead to the maximum total profit for the players. An alternative solution is for the lessor and lessee to act cooperatively in order to increase their total profit (Cachon \& Zipkin, 1999; Nagarajan \& Sošić, 2008).

\subsection{Maximum Total Profit}

In a cooperative regime, the strategy set of the lessee and lessor is $X=\{(r, K, N, \delta) \mid 0 \leq$ $r \leq r_{m}, \quad 0 \leq K \leq L, \quad N \geq 0$ integer, $\left.\quad 0 \leq \delta \leq 1\right\}$. The players choose the set of strategies $\mathbf{x}_{c}^{*} \in X$ that solves $\max _{\mathbf{x}}\{\Pi\}=\max _{\mathbf{x}}\left\{\Pi_{1}(\mathbf{x})+\Pi_{2}(\mathbf{x})\right\}$ where $\Pi_{1}$ and $\Pi_{2}$ are the payoffs of the lessee and the lessor given in (15) and (16), respectively. The cooperative solution is obtained by solving the following problem:

$$
\begin{array}{ll}
\max _{r, K, N, \delta} & \Pi=\frac{u_{m} r K}{r_{m} L}\left[L-\frac{K(N \delta+1)}{2(N+1)}\right]-N a-\frac{N b K(1-\delta)}{(N+1)}-K^{2} C_{f}\left(\theta_{1} r+\theta_{2}\right) \frac{(N \delta+1)}{2(N+1)} \\
& -K^{2}\left(\theta_{3} r^{2}+\theta_{4}\right) \frac{(N \delta+1)^{2}}{(N+1)^{2}} \\
\text { s.t. } \quad & 0 \leq r \leq r_{m} \\
& 0 \leq K \leq L \\
& N \geq 0 \text { integer } \\
& 0 \leq \delta \leq 1
\end{array}
$$

In the problem formulation, the lessee and lessor seek to jointly maximize the sum of their profits. The following proposition characterizes the optimum solution (see Appendix for the proof).

Proposition 6. The solution that maximizes the total profit $\Pi$ is $\mathbf{x}_{c}^{*}=\left(r_{c}^{*}, K_{c}^{*}, N_{c}^{*}, \delta_{c}^{*}\right)=$ $\left(r_{m}, L, N^{*}, 0\right)$, where $N^{*}=\frac{1}{3 a}\left(C+\frac{3 a B}{C}\right)-1$, with $B=\frac{K^{2}}{2}\left(\frac{u_{m}}{L}+C_{f}\left(\theta_{1} r+\theta_{2}\right)\right)-b K$, $C=\sqrt[3]{\frac{54 a^{2} K^{2}\left(\theta_{3} r^{2}+\theta_{4}\right)+\sqrt{-27 a^{2} Q}}{2}}$, and $Q=4 a B^{3}-108 a^{2} K^{4}\left(\theta_{3} r^{2}+\theta_{4}\right)^{2}$.

In this paper, we call the solution $\mathbf{x}_{c}^{*}$ the total maximum solution or the cooperative solution. Again, if $N^{*}$ is not an integer, we can use the same technique mentioned after Proposition 3. Besides, the following result regarding $N^{*}$ can be obtained (see Appendix for the proof).

Proposition 7. $N^{*}$ is the unique maximum. 
These two propositions indicate that the cooperative solution $\mathbf{x}_{\mathbf{c}}^{*}$, which maximizes the sum of the lessor's and the lessee's profits, is the unique strategy vector, for which the optimum usage rate equals the maximum usage rate $r_{c}^{*}=r_{m}$, lease period is the equipment's life cycle $K_{c}^{*}=L$, number of PM is unique $N_{c}^{*}=N^{*}$, and degree of each maintenance is $\delta_{c}^{*}=0$ (perfect maintenance).

\subsection{Comparison of the Non-cooperative and Cooperative Solutions}

By comparing the non-cooperative and cooperative solutions, the following useful managerial insights can be obtained (see Appendix for the proof).

Proposition 8. The lessor's numbers of PM in both the Nash and the Stackelberg equilibria are less than the one in the total maximum solution $\left(N^{*}>N_{2}^{*}>N_{3}^{*}\right.$ and $N^{*}>$ $\left.N_{2}^{*}>N_{4}^{*}\right)$.

Proposition 9. The lessee's usage rates in both the Nash and the Stackelberg equilibria are not higher than the one in the total maximum solution $\left(r_{1}^{*}(N)<r_{m}\right)$.

These two propositions indicate that the maintenance quality for the equipment under the cooperative contract is better than the ones under both non-cooperative alternatives. Besides, the equipment's usage rate under the cooperative contract is higher than those under the non-cooperative ones. In other words, competition lowers both the usage rate and the maintenance quality of the leased equipment. It should be noted that the noncooperative and cooperative schemes result in the same lease period $(K)$ and PM degree $(\delta)$. Since the Nash and Stackelberg equilibria are different from the total maximum solution, the following result is expected (see Appendix for the proof).

Proposition 10. The total profit in the cooperative scheme is higher than the total profits in both the Nash and Stackelberg equilibria.

This proposition is a well-known general result in the literature, which means that the lessor and the lessee can increase their total profit by switching to the cooperative contract and choosing the total maximum solution $\mathbf{x}_{c}^{*}$. That is $\Pi\left(\mathbf{x}_{c}^{*}\right)>\Pi\left(\mathbf{x}_{n}^{*}\right)$, and $\Pi\left(\mathbf{x}_{c}^{*}\right)>\Pi\left(\mathbf{x}_{s}^{*}\right)$ where $\Pi$ is the sum of the profits of the players as $\Pi=\Pi_{1}+\Pi_{2}$. Next, we define $\Delta \Pi$ as:

$$
\Delta \Pi=\Pi\left(\mathbf{x}_{c}^{*}\right)-\Pi\left(\mathbf{x}_{n}^{*}\right)=\Pi_{1}\left(\mathbf{x}_{c}^{*}\right)+\Pi_{2}\left(\mathbf{x}_{c}^{*}\right)-\Pi_{1}\left(\mathbf{x}_{n}^{*}\right)-\Pi_{2}\left(\mathbf{x}_{n}^{*}\right)>0
$$

We call $\Delta \Pi$ the joint profit gain, which is the profit the players jointly achieve by moving from the Nash scheme to the cooperative contract. Similarly, the joint profit gain for switching from Stackelberg equilibria to the total maximum solution can be determined by substituting $\mathbf{x}_{s}^{*}$ for $\mathbf{x}_{n}^{*}$ in $(28)$. 


\subsection{Transfer-payment Contract}

In this section, we demonstrate that the cooperative solution can be implemented under transfer-payment (or side-payment) contracts. There are two criteria for a proper sidepayment contract to satisfy (Leng \& Zhu, 2009). First, selecting the total maximum solution should make each player better off compared to the non-cooperative alternatives. Otherwise, the player who is worse off loses his incentive to cooperate and won't choose the total maximum solution. Second, to avoid probable deviations of the players, the total maximum solution should be an equilibrium for the side-payment contract (Moses $\&$ Seshadri, 2000). To satisfy these two criteria, we propose a transfer-payment from the lessor to lessee with three parameters $\left(\gamma, \bar{\alpha}_{0}, \beta\right)$ as:

$$
H(\mathbf{x})=\gamma+\bar{\alpha}_{0} r^{2} K+\frac{\beta}{N+1}
$$

The transfer payment $H(\mathbf{x})$ modifies the payoff functions of the lessor and lessee in (15) and (16), respectively, to:

$$
\begin{aligned}
& \bar{\Pi}_{1}(\mathbf{x})=\Pi_{1}(\mathbf{x})+H(\mathbf{x}) \\
& \bar{\Pi}_{2}(\mathbf{x})=\Pi_{2}(\mathbf{x})-H(\mathbf{x})
\end{aligned}
$$

The desired value of constant parameter $\gamma$ needs to be such that both the lessor and lessee are better off by cooperation (satisfying the first criterion) and the set of two parameters $\left(\bar{\alpha}_{0}, \beta\right)$ such that the total optimal solution $\mathbf{x}_{c}^{*}=\left(r_{m}, L, N^{*}, 0\right)$ is an equilibrium for the modified game with side-payment (satisfying the second criterion).

In order to determine $\gamma$, we assume that the lessor and lessee negotiate over the share of the maximum total profit. We allocate the profit based on Nash Bargaining solution since it's simple and robust, besides empirical evidence supports this solution compared to other alternatives (Nagarajan \& Bassok, 2008). The following result determines the constant side-payment term $\gamma$ based on this solution. See Muthoo (1999) and Leng \& Zhu (2009) for proof.

Proposition 11. If the players equally distribute the joint profit gain, $\Delta \Pi$, as suggested by the Nash bargaining solution, then $\gamma$ is determined as follows:

$$
\gamma=\frac{\sum_{i=1}^{2}(-1)^{i}\left[\Pi_{i}\left(\mathbf{x}_{c}^{*}\right)+(-1)^{i+1}\left(\bar{\alpha}_{0} r_{m}^{2} L+\frac{\beta}{N+1}\right)-\Pi_{i}\left(\mathbf{x}_{n}^{*}\right)\right]}{2}
$$

where $\Delta \Pi$ is defined in (28). This proposition states that when the players negotiate in cooperation, they agree to give each other the Nash profits $\Pi_{1}\left(\mathbf{x}_{n}^{*}\right)$ and $\Pi_{2}\left(\mathbf{x}_{n}^{*}\right)$, which are the payoffs they will obtain if they do not cooperate at all, and moreover, they equally 
split the joint profit gain, $\Delta \Pi$. The constant value $\gamma$ motivates the players to cooperate and to choose the total maximum solution $\mathbf{x}_{c}^{*}$, by ensuring that the lessee's net profit of $\bar{\Pi}_{1}\left(\mathbf{x}_{c}^{*}\right)$ and the lessor's profit of $\bar{\Pi}_{2}\left(\mathbf{x}_{c}^{*}\right)$ are $\Delta \Pi / 2$ higher than the non-cooperative profits. Similarly, the value of $\gamma$ for the Stackelberg game can be determined by substituting $\mathbf{x}_{s}^{*}$ for $\mathbf{x}_{n}^{*}$.

Next, we determine proper values of $\bar{\alpha}_{0}$ and $\beta$ such that the total optimal solution $\left(r_{m}, L\right)$ is the best response for the lessee and $\left(N^{*}, 0\right)$ is the best response for the lessor. Based on the two cases of Nash equilibrium in Theorem 1, two side-payment contracts are designed and presented in Propositions 12 and 13 (see Appendix for the proofs).

Proposition 12. In the case of $D_{1}<0$, a proper side-payment contract is $H(\mathbf{x})=$ $\gamma+\bar{\alpha}_{0} r^{2} K+\frac{u_{m} L}{2(N+1)}$, where $\bar{\alpha}_{0}$ satisfies relation $\bar{\alpha}_{0} \geq \alpha_{0}-\frac{u_{m}\left(2 N^{*}+1\right)}{4 r_{m}^{2}\left(N^{*}+1\right)}$.

Based on the proposition, a proper transfer function which makes the the total maximum solution $\left(r_{m}, L\right)$ the best response for the lessee is $\bar{\alpha}_{0} r^{2} K$. One interpretation of this function is that the lessor is reducing the original price function from $\alpha_{0} r^{2} K$ to $\left(\alpha_{0}-\bar{\alpha}_{0}\right) r^{2} K$ to make the total maximum solution the best response for the lessee. The next term in the transfer function, $\frac{u_{m} L}{2(N+1)}\left(\right.$ or $\left.\beta=\frac{u_{m} L}{2}\right)$, makes $\left(N^{*}, 0\right)$ the best response of the lessor and can be interpreted as the penalty the lessee charges the lessor for the revenue loss caused by deterioration of the equipment (see section 2.4). This penalty function is decreasing in $N$, since better maintenance quality decreases the loss of revenue. As a result, the transfer function $\bar{\alpha}_{0} r^{2} K+\frac{u_{m} L}{2(N+1)}$ makes the total optimal solution a Nash equilibrium for the game (satisfying the second criterion), and the fixed transfer payment $\gamma$ ensures that this contract is beneficial for both parties (satisfying the first criterion).

Proposition 13. In the case of $C_{1}>0$ and $D_{1}>0$, the unique proper side-payment contract is $H(\mathbf{x})=\gamma+\frac{u_{m} L}{2(N+1)}$, where $\gamma \leq 0$.

It can be seen that when $C_{1}>0$ and $D_{1}>0$ (case $i i$ of Theorem 1 ), the total maximum solution $\left(r_{m}, L\right)$ is already the best response of the lessee so $\bar{\alpha}_{0}=0$. In order to make $N^{*}$ the best response of the lessor, we use the transfer function $\frac{u_{m} L}{2(N+1)}$, same as Proposition 12. This is the unique function that makes the first order derivative of the lessor's payoff function identical to that of the total payoff function. $\gamma \leq 0$ shows that the lessee transfers the value $|\gamma|$ to the lessor to motivate him to cooperate and choose the total maximum solution $N^{*}$.

It should be noted that in our case, the transfer functions in Propositions 12 and 13 are the same for both simultaneous and Stackelberg games cases $i$ and $i i$. The reason is that the lessee's (follower's) best response $\left(r_{m}, L\right)$ is constant in terms of $N$ and $\delta$, and substituting $\left(r_{m}, L\right)$ in the lessor's (leader's) payoff $\bar{\Pi}_{2}$ doesn't change the lessor's 
best response. A similar approach is needed to determine the transfer function for the cases $i$ ii and $i v$ of the leader-follower game. Generally, the side-payment functions of the simultaneous and Stackelberg game are different when the best response of the follower is a function of the leader's strategies. Another point is that although the choice of transfer payment function $\frac{u_{m} L}{2(N+1)}$ is unique, the transfer function $\alpha_{0} r^{2} K$ is not unique. Our proposed transfer function $\bar{\alpha}_{0} r^{2} K$ is in the form of our original price function $\alpha_{0} r^{2} K$, which can properly coordinate the players, and has a nice price discount interpretation and implementation. Besides, although the transfer payment $\gamma$ is essential in assuring that the contract is attractive for both lessor and lessee, it has no impact on the total maximum solution and profit or on the strategies each of the lessor and the lessee will choose. The following three-step process can be used to derive a proper side-payment contract $H(\mathbf{x})$ :

1. Derive the Nash equilibrium $\mathbf{x}_{n}^{*}$ using Theorem 1 , and compute the corresponding total profit $\Pi\left(\mathbf{x}_{n}^{*}\right)=\Pi_{1}\left(\mathbf{x}_{n}^{*}\right)+\Pi_{2}\left(\mathbf{x}_{n}^{*}\right)$.

2. Derive the total maximum solution $\mathbf{x}_{c}^{*}$ using Proposition 6, and compute the maximum total profit $\Pi\left(\mathbf{x}_{c}^{*}\right)=\Pi_{1}\left(\mathbf{x}_{c}^{*}\right)+\Pi_{2}\left(\mathbf{x}_{c}^{*}\right)$.

3. Calculate the joint profit gain $\Delta \Pi$ and three parameters $\left(\gamma, \bar{\alpha}_{0}, \beta\right)$ based on Propositions 11-13.

The same process can be used to derive a proper side-payment contract in leader-follower scenario by considering Stackelberg equilibrium.

\section{Numerical Example}

We have shown that cooperation can increase the total profit of the players. In this section, a numerical study is carried out to illustrate how large the value of cooperation can be. To this end, we consider both the simultaneous and Stackelberg games described in Sections 3.3 and 3.4, and compare their total profits with the maximum total profit.

We consider leasing a vehicle with the following parameters. The initial value of the vehicle is $V_{0}=\$ 20,000$, and its failure intensity is the one in (7). Its life cycle is $L=10$ years, and the maximum usage rate of the vehicle is $r_{m}=20,000$ miles/year. If the lessee leases the vehicle for one year at the maximum usage rate $r_{m}=20,000$, he needs to pay the lessor $\$ 2,800\left(\alpha_{0}=7 \times 10^{-6}\right)$. The vehicle generates up to $\$ 6,000$ annual revenue $\left(u_{m}=\$ 6,000 /\right.$ year $)$ for the lessee, and the salvage value of the vehicle is $\$ 2,000$ after 10 years of usage at the highest annual usage rate $\left(r_{m}\right)$. 
Fig. 2 shows the total profits of the non-cooperative contracts, $\Pi\left(\mathbf{x}_{n}^{*}\right)$ and $\Pi\left(\mathbf{x}_{s}^{*}\right)$, as a percentage of the maximum total profit $\Pi\left(\mathbf{x}_{c}^{*}\right)$ in the cooperative solution. It can be seen that cooperation can increase the players' total profit, but the magnitude of increase is case specific. As an example, when $u_{m}=\$ 3,600 /$ year the total profits under the Nash and Stackelberg games are $51.58 \%$ and $53.69 \%$ of the maximum total profit, respectively, indicating that the value of cooperation is significant; while when $u_{m}=\$ 6000 /$ year the two quantities are around 99\%, suggesting that cooperation can increase the total profit for only one percent. According to the analytical results of Theorem 1, one can see that
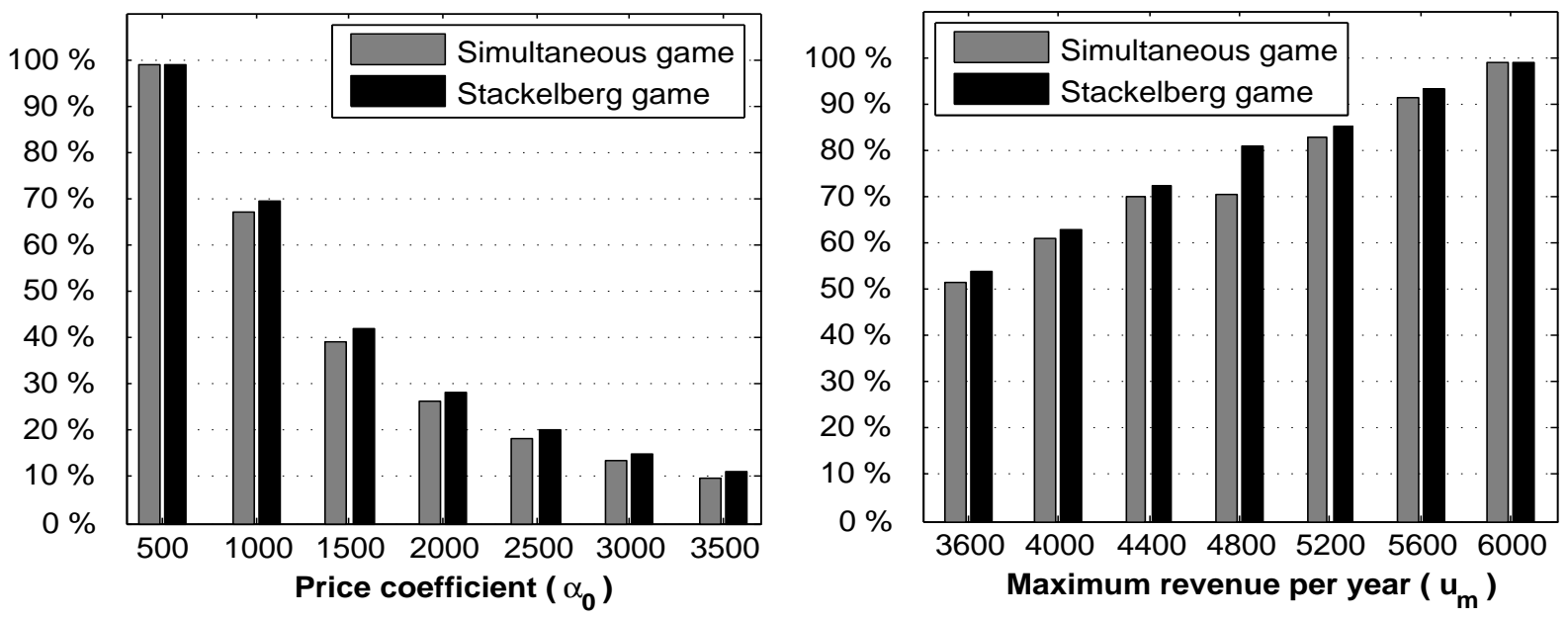

Fig. 2. Total profits of non-cooperative contracts as a percentage of total profit in cooperative one

when $D_{1}=u_{m}\left(2 N_{n}^{*}+1\right)-4\left(N_{n}^{*}+1\right) \alpha_{0} r_{m}^{2}>0$ (i.e., the revenue $u_{m}$ is high enough or the price $\alpha_{0}$ is low) the non-cooperative strategy $\mathbf{x}_{n}^{*}$ is similar to the cooperative one $\mathbf{x}_{c}^{*}$ except for the number of PM, $N$. In this case, the performance of the non-cooperative solution is nearly as good as the cooperative solution, but when $D_{1}<0$ the non-cooperative strategy $\mathbf{x}_{n}^{*}$ differs from the cooperative one $\mathbf{x}_{c}^{*}$ in both $r$ and $N$. In this case, the value of cooperation can be substantial, so engaging the lessor and lessee in price negotiation is encouraged.

Table 1 shows the strategies and payoffs in both simultaneous move and Stackelberg non-cooperative contracts and the corresponding strategies and payoffs in the cooperative scheme. When $u_{m}=\$ 3,600 /$ year, the usage rate that the lessee chooses in the simultaneous move game is $r_{n}^{*}=12,214$ miles/year, and the number of PM the lessor chooses is $N_{n}^{*}=9$. Next, if the players choose to cooperate the lessee chooses the maximum usage rate $r_{c}^{*}=20,000$ miles/year, and the lessor chooses $N_{c}^{*}=19$. As a result of this contract, 
the lessee's profit increases from $\$ 10,440$ to $\$ 17,119.5$ and the lessor's profit from $\$ 3,796$ to $\$ 10,475.5$. One can see that the cooperative scheme can result in major performance improvements for the two players in this case. However, when $u_{m}=\$ 6000 /$ year (high revenue) the lessee has enough motivation to lease the vehicle at the maximum annual usage rate $r_{n}^{*}=20,000$ miles in the non-cooperative contract. In this case should the players wish to cooperate, the lessor increases the number of PM from $N_{n}^{*}=13$ to $N_{c}^{*}=22$. The profit of lessee as a result of switching to the cooperative contract increases from $\$ 29,857$ to $\$ 30,110$, and the lessor's profit increases from $\$ 20,667$ to $\$ 20,920$, which are not considered major improvements. It should be noted that the optimal lease periods for all the games in the table are $K=10$ years, and the corresponding degrees of PM are $\delta=0$.

Table 1. Non-cooperative and cooperative strategies and payoffs

\begin{tabular}{|c|c|c|c|c|c|c|c|c|c|c|c|}
\hline & \multirow[b]{2}{*}{$\begin{array}{c}\text { Max revenue } \\
u_{m}(\$ / y)\end{array}$} & \multicolumn{5}{|c|}{ Non-cooperative } & \multicolumn{5}{|c|}{ Cooperative } \\
\hline & & $\begin{array}{c}\text { Usage } \\
r_{n_{s}}^{*}(\text { miles } / y)\end{array}$ & $\begin{array}{l}\mathrm{PM} \\
N_{n, s}^{*}\end{array}$ & $\begin{array}{l}\text { Lessee } \\
\Pi_{1}(\$)\end{array}$ & $\begin{array}{l}\text { Lessor } \\
\Pi_{2}(\$)\end{array}$ & $\begin{array}{c}\text { Total } \\
(\$)\end{array}$ & $\begin{array}{c}\text { Usage } \\
r_{c}^{*}(\text { miles } / y)\end{array}$ & $\begin{array}{l}\mathrm{PM} \\
N_{c}^{*}\end{array}$ & $\begin{array}{c}\text { Lessee } \\
\bar{\Pi}_{1}(\$)\end{array}$ & $\begin{array}{c}\text { Lessor } \\
\bar{\Pi}_{2}(\$)\end{array}$ & $\begin{array}{l}\text { Total } \\
\Pi(\$)\end{array}$ \\
\hline \multirow{5}{*}{ 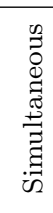 } & 3600 & 12214 & 9 & 10440 & 3796 & 14236 & 20000 & 19 & 17119.5 & 10475.5 & 27595 \\
\hline & 4000 & 13636 & 10 & 13017 & 6225 & 19242 & 20000 & 19 & 19143.5 & 12351.5 & 31495 \\
\hline & 4400 & 15060 & 11 & 15875 & 8952 & 24827 & 20000 & 20 & 21160 & 14237 & 35397 \\
\hline & 4800 & 16429 & 11 & 17351 & 10366 & 27717 & 20000 & 20 & 23143.5 & 16148.5 & 39302 \\
\hline & 6000 & 20000 & 13 & 29857 & 20667 & 50524 & 20000 & 22 & 30110 & 20920 & 51030 \\
\hline \multirow{5}{*}{ 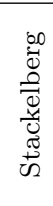 } & 3600 & 12429 & 14 & 10813 & 4005 & 14818 & 20000 & 19 & 17201.5 & 10393.5 & 27595 \\
\hline & 4000 & 13839 & 15 & 13407 & 6454 & 19861 & 20000 & 19 & 19224 & 12271 & 31495 \\
\hline & 4400 & 15278 & 17 & 16339 & 9195 & 25534 & 20000 & 20 & 21270.5 & 14126.5 & 35397 \\
\hline & 4800 & 16692 & 18 & 19503 & 12226 & 31729 & 20000 & 20 & 23289.5 & 16012.5 & 39302 \\
\hline & 6000 & 20000 & 13 & 29857 & 20667 & 50524 & 20000 & 22 & 30110 & 20920 & 51030 \\
\hline
\end{tabular}

Note that when comparing the Nash and Stackelberg games, it is clear that the lessor is always better off with the leader-follower scheme. In this example, the lessee is also better off with the Stackelberg game (which is not a general result based on Proposition $5)$.

The results given in Table 1 are also shown in Fig. 3 where the relative increases of usage rate $(r)$ in the cooperative contract over the non-cooperative alternatives are defined as $\frac{r_{c}^{*}-r_{n}^{*}}{r_{n}^{*}} 100 \%$ and $\frac{r_{c}^{*}-r_{s}^{*}}{r_{s}^{*}} 100 \%$, respectively for simultaneous and Stackelberg games, as revenue $u_{m}$ increases. In the same manner, the relative increases in the number of PM $N$ and the profits of the lessee and lessor are also presented. It can be seen that when $u_{m}=\$ 6000 /$ year (high revenue) the relative increase in usage rate is zero (usage rate is 20, 000 (miles/year) in both the non-cooperative and cooperative solutions). In this case, the number of PM increases for $69.23 \%$ as a result of cooperation, which increases the lessee's profit only by $0.84 \%$ and the lessor's profit by $1.22 \%$, but when $u_{m}=\$ 3600 /$ year, 
cooperation increases the lessee's profit by $63.97 \%$ and the lessor's profit by $175.96 \%$ which is a significant increase in profits.
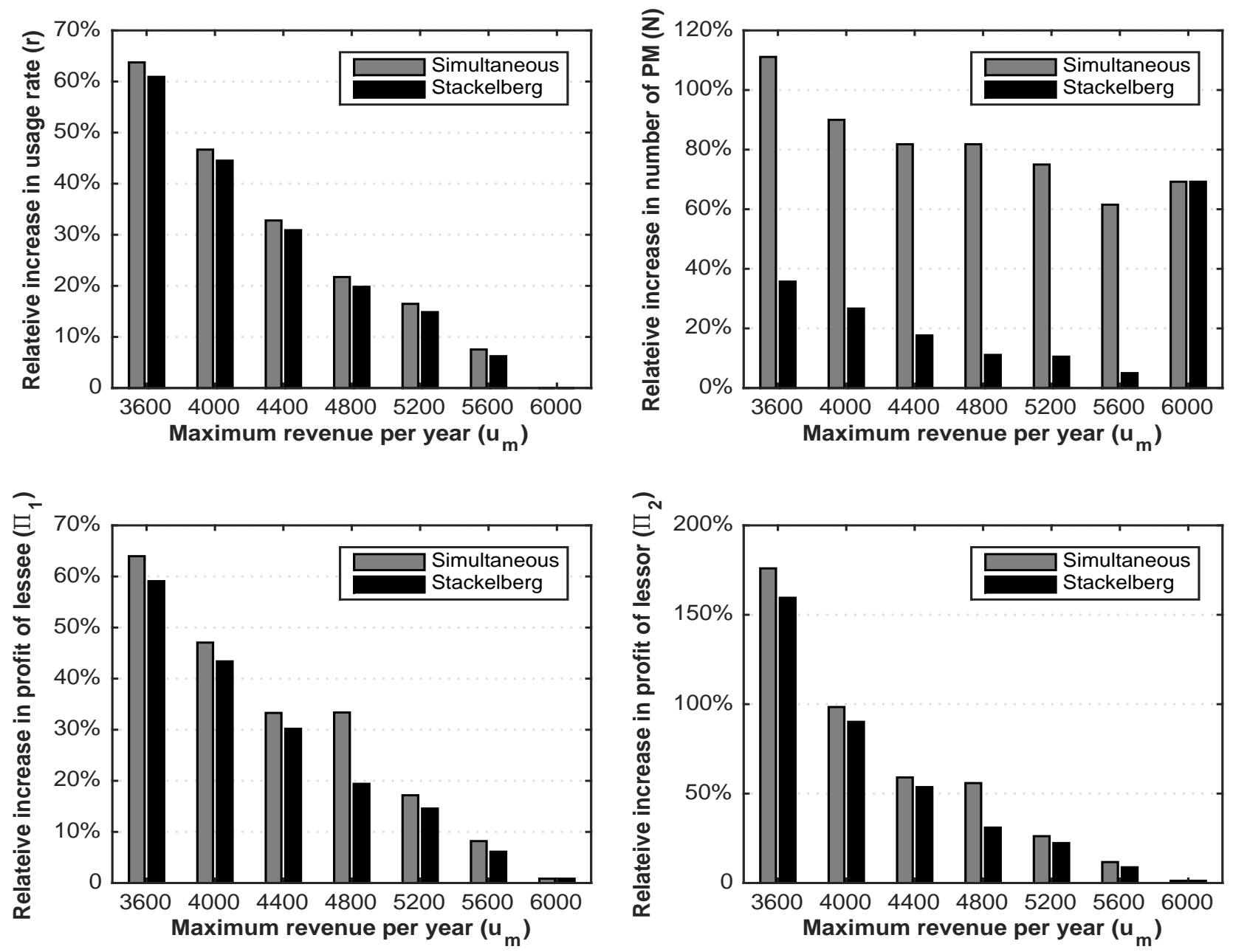

Fig. 3. Relative increases in $r, N, \Pi_{1}$, and $\Pi_{2}$ by switching from the non-cooperative contracts to the cooperative one

\section{Conclusion}

In this paper, we modeled two non-cooperative lease contracts considering Nash and Stackelberg equilibria and a cooperative one aiming at maximizing the total payoff of the players. We showed that the Nash and Stackelberg equilibria are different from the total maximum solution, and thus the players can increase their total profit by cooperation. Implementation of the cooperative solution requires two major criteria. We have shown 
that these two criteria can be achieved by a nonlinear transfer-payment contract. Our results illustrate that cooperation can be regarded as a value-added strategy in establishing such lease contracts. Besides, our numerical results show that while cooperation always increases the total profit, the magnitude of increase is case specific. When the lease price is low or the revenue is high, the profits in the non-cooperative contracts will be close to the cooperative alternative, while in other cases the cooperation may increase the total profit significantly.

An interesting direction for a future research is to consider cases where there are several players with different payoff parameters. The development of such models will provide insights into the effect of increased competition on lease contracting.

\section{Acknowledgment}

This work is supported in part by the US National Science Foundation under Grant \#CMMI-1238304.

\section{References}

Al-Najjar, B., \& Alsyouf, I. (2004). Enhancing a company's profitability and competitiveness using integrated vibration-based maintenance: A case study. European Journal of Operational Research, 157(3), 643-657.

Bajari, P., McMillan, R., \& Tadelis, S. (2009). Auctions versus negotiations in procurement: An empirical analysis. Journal of Law, Economics, and Organization, 25(2), $372-399$.

Bartholomew-Biggs, M., Zuo, M. J., \& Li, X. (2009). Modelling and optimizing sequential imperfect preventive maintenance. Reliability Engineering 85 System Safety, 94(1), $53-62$.

Cachon, G. P. (2003). Supply chain coordination with contracts. Handbooks in Operations Research and Management Science, 11, 227-339.

Cachon, G. P., \& Zipkin, P. H. (1999). Competitive and cooperative inventory policies in a two-stage supply chain. Management Science, 45(7), 936-953.

Chang, W. L., \& Lo, H. C. (2011). Joint determination of lease period and preventive maintenance policy for leased equipment with residual value. Computers $\&$ Industrial Engineering, 61(3), 489-496. 
Chen, F., Federgruen, A., \& Zheng, Y. (2001). Coordination mechanisms for a distribution system with one supplier and multiple retailers. Management Science, 47(5), 693708.

Chen, T., \& Popova, E. (2002). Maintenance policies with two-dimensional warranty. Reliability Engineering \& System Safety, 77(1), 61-69.

Chiu, C. H., Choi, T. M., Li, Y., \& Xu, L. (2014). Service competition and service war: a game-theoretic analysis. Service Science, 6(1), 63-76.

Dong, J., Zhang, D., \& Nagurney, A. (2004). A supply chain network equilibrium model with random demands. European Journal of Operational Research, 156 (1), 194-212.

Esmaeili, M., Aryanezhad, M. B., \& Zeephongsekul, P. (2009). A game theory approach in seller-buyer supply chain. European Journal of Operational Research, 195(2), $442-448$.

Esmaeili, M., Gamchi, N. S., \& Asgharizadeh, E. (2014). Three-level warranty service contract among manufacturer, agent and customer: A game-theoretical approach. European Journal of Operational Research, 239(1), 177-186.

Giannoccaro, I., \& Pontrandolfo, P. (2004). Supply chain coordination by revenue sharing contracts. International Journal of Production Economics, 89(2), 131-139.

Giddy, I. (2004). Equipment leasing. http://people.stern.nyu.edu/igiddy/leasing.htm.

Gurnani, H., \& Shi, M. (2006). A bargaining model for a first-time interaction under asymmetric beliefs of supply reliability. Management Science, 52(6), 865-880.

Huang, Y., \& Yen, C. (2009). A study of two-dimensional warranty policies with preventive maintenance. IIE Transactions, 41(4), 299-308.

Iskandar, B. P., \& Murthy, D. (2003). Repair-replace strategies for two-dimensional warranty policies. Mathematical and Computer Modelling, 38(11), 1233-1241.

Iskandar, B. P., Murthy, D. P., \& Jack, N. (2005). A new repair-replace strategy for items sold with a two-dimensional warranty. Computers $\&$ Operations Research, 32(3), 669-682.

Jack, N., Iskandar, B. P., \& Murthy, D. P. (2009). A repair-replace strategy based on usage rate for items sold with a two-dimensional warranty. Reliability Engineering 8 System Safety, 94(2), 611-617.

Jaturonnatee, J., Murthy, D., \& Boondiskulchok, R. (2006). Optimal preventive maintenance of leased equipment with corrective minimal repairs. European Journal of Operational Research, 174(1), 201-215. 
Kahle, W. (2007). Optimal maintenance policies in incomplete repair models. Reliability Engineering 8 System Safety, 92(5), 563-565.

Kijima, M. (1989). Some results for repairable systems with general repair. Journal of Applied Probability, 26, 89-102.

Kim, C., Djamaludin, I., \& Murthy, D. (2004). Warranty and discrete preventive maintenance. Reliability Engineering 85 System Safety, 84(3), 301-309.

Kim, H. G., \& Rao, B. (2000). Expected warranty cost of two-attribute free-replacement warranties based on a bivariate exponential distribution. Computers $\&$ Industrial Engineering, 38(4), 425-434.

Kim, S. L., \& Ha, D. (2003). A JIT lot-splitting model for supply chain management: Enhancing buyer-supplier linkage. International Journal of Production Economics, $86(1), 1-10$.

Leng, M., \& Parlar, M. (2005). Game theoretic applications in supply chain management: A review. Information Systems and Operations Research, 43(3), 187-230.

Leng, M., \& Parlar, M. (2010). Game-theoretic analyses of decentralized assembly supply chains: Non-cooperative equilibria vs. coordination with cost-sharing contracts. European Journal of Operational Research, 204(1), 96-104.

Leng, M., \& Zhu, A. (2009). Side-payment contracts in two-person nonzero-sum supply chain games: Review, discussion and applications. European Journal of Operational Research, $196(2), 600-618$.

Levitin, G., \& Lisnianski, A. (2000). Optimization of imperfect preventive maintenance for multi-state systems. Reliability Engineering 63 System Safety, 67(2), 193-203.

Marais, K. B., \& Saleh, J. H. (2009). Beyond its cost, the value of maintenance: an analytical framework for capturing its net present value. Reliability Engineering 8 System Safety, 94(2), 644-657.

Matsumoto, A., \& Szidarovszky, F. (2016). Game Theory and Its Applications. SpringerVerlag, Tokyo.

Monga, A., \& Zuo, M. J. (2001). Optimal design of series-parallel systems considering maintenance and salvage value. Computers \& Industrial Engineering, 40(4), 323337.

Moses, M., \& Seshadri, S. (2000). Policy mechanisms for supply chain coordination. IIE Transactions, 32(3), 245-262.

Murthy, D., \& Jack, N. (2014). Extended Warranties, Maintenance Service and Lease Contracts. Springer, London. 
Muthoo, A. (1999). Bargaining Theory with Applications. Cambridge University Press, Cambridge.

Nagarajan, M., \& Bassok, Y. (2008). A bargaining framework in supply chains: The assembly problem. Management Science, 54(8), 1482-1496.

Nagarajan, M., \& Sošić, G. (2008). Game-theoretic analysis of cooperation among supply chain agents: Review and extensions. European Journal of Operational Research, $187(3), 719-745$.

Osborne, M. J., \& Rubinstein, A. (1994). A course in game theory. MIT Press, Cambridge.

Pongpech, J., \& Murthy, D. (2006). Optimal periodic preventive maintenance policy for leased equipment. Reliability Engineering \&5 System Safety, 91(7), 772-777.

Shafiee, M., \& Chukova, S. (2013). Maintenance models in warranty: A literature review. European Journal of Operational Research, 229(3), 561-572.

Tarakci, H., Tang, K., Moskowitz, H., \& Plante, R. (2006). Incentive maintenance outsourcing contracts for channel coordination and improvement. IIE Transactions, $38(8), 671-684$.

Wang, Y., Wallace, S. W., Shen, B., \& Choi, T. M. (2015). Service supply chain management: A review of operational models. European Journal of Operational Research, $247(3), 685-698$.

Wu, J., Xie, M., \& Ng, T. S. A. (2011). On a general periodic preventive maintenance policy incorporating warranty contracts and system ageing losses. International Journal of Production Economics, 129(1), 102-110.

Yeh, R. H., \& Chen, C. K. (2006). Periodical preventive-maintenance contract for a leased facility with weibull life-time. Quality and Quantity, 40(2), 303-313.

Yeh, R. H., Kao, K. C., \& Chang, W. L. (2009). Optimal preventive maintenance policy for leased equipment using failure rate reduction. Computers $\& 5$ Industrial Engineering, 57(1), 304-309.

Yeh, R. H., Lo, H. C., \& Yu, R. Y. (2011). A study of maintenance policies for second-hand products. Computers \& Industrial Engineering, 60(3), 438-444.

\section{Appendix}

Proof of Proposition 1. The problem to be solved is $\max _{r, K} \Pi_{1}(r, K)$. We consider a two-step optimization approach: in the first step, we find $r_{o p t}$ as the usage rate that 
maximizes the payoff function for a given value of $(N, \delta)$; and next, we determine $K_{\text {opt }}$ , as the optimum lease period that maximizes the payoff function for the value of $r_{\text {opt }}$ determined in the first step. After taking the first order derivative with respect to $r$, one can see that:

- If $\frac{u_{m}}{2 \alpha_{0} r_{m} L}\left[L-\frac{K(N \delta+1)}{2(N+1)}\right]>r_{m}$, then $r_{o p t}=r_{m}$. After substituting $r_{m}$ into the objective function and taking the first order derivative with respect to $K$, two cases can be seen: (1) if $0<\frac{(N+1)}{(N \delta+1)}\left[L-\frac{\alpha_{0} r_{m}^{2} L}{u_{m}}\right]<L$ then $K_{\text {opt }}=\frac{(N+1)}{(N \delta+1)}\left[L-\frac{\alpha_{0} r_{m}^{2} L}{u_{m}}\right]$ (case iii. of Proposition 1), and (2) if $\frac{(N+1)}{(N \delta+1)}\left[L-\frac{\alpha_{0} r_{m}^{2} L}{u_{m}}\right]>L$ then $K_{o p t}=L$ (case ii.).

- If $0<\frac{u_{m}}{2 \alpha_{0} r_{m} L}\left[L-\frac{K(N \delta+1)}{2(N+1)}\right] \leq r_{m}$, then $r_{o p t}=\frac{u_{m}}{2 \alpha_{0} r_{m} L}\left[L-\frac{K(N \delta+1)}{2(N+1)}\right]$. Taking the first order derivative of the objective function with respect to $K$ and substituting $r_{o p t}$ for $r$ two cases can be seen: (1) if $L<\frac{2 L(N+1)}{3(N \delta+1)}$ then $K_{o p t}=L$ (case $i$.), and (2) if $L>\frac{2 L(N+1)}{3(N \delta+1)}$ then $K_{o p t}=\frac{2 L(N+1)}{3(N \delta+1)}$ (case $i v$.).

Table 2. Optimality conditions for Proposition 1

\begin{tabular}{c|cccc|c|c|cccc|c}
\hline$\#$ & $A_{1}$ & $B_{1}$ & $C_{1}$ & $D_{1}$ & $O p t$ & $\#$ & $A_{1}$ & $B_{1}$ & $C_{1}$ & $D_{1}$ & $O p t$ \\
\hline 1 & + & + & + & + & $i i$. & 9 & + & + & - & - & $\operatorname{Imp}$ \\
2 & + & + & + & - & Imp & 10 & + & - & - & + & $\operatorname{Imp}$ \\
3 & + & + & - & + & Imp & 11 & + & - & + & - & $i$. \\
4 & + & - & + & + & $i i$. & 12 & + & - & - & - & $i$. \\
5 & - & + & + & + & $i i$. & 13 & - & - & - & + & $\operatorname{Imp}$ \\
6 & - & - & + & + & Imp & 14 & - & + & - & - & $i i i$. \\
7 & - & + & - & + & $i i i$. & 15 & - & - & + & - & $\operatorname{Imp}$ \\
8 & - & + & + & - & Imp & 16 & - & - & - & - & $i v$. \\
\hline
\end{tabular}

Table 2 gives sixteen cases considering the signs of $A_{1}, B_{1}, C_{1}$ and $D_{1}$. The optimal solutions are summarized in columns 6 and 12 (Opt) where the numbers $i$. to $i v$. correspond to Proposition 1. The impossible cases denoted by $\operatorname{Imp}$ are impossible cases explained as follows. Observe that $D_{1}=C_{1}+(N+1) B_{1}$, so when $B_{1}>0$ and $C_{1}>0$ we should have $D_{1}>0$ making cases \#2 and \#8 impossible; if $B_{1}<0$ and $C_{1}<0$, then $D_{1}<0$ making cases \#10 and \#13 impossible. Another property is $N(1-\delta) B_{1}+A_{1} \alpha_{0} r_{m}^{2}=C_{1}$, so for $A_{1}>0$ and $B_{1}>0$ we should have $C_{1}>0$; for $A_{1}<0$ and $B_{1}<0$, we should have $C_{1}<0$ making cases $\# 3, \# 6, \# 9$, and \#15 impossible. It is worth pointing out that the same optimization results can be derived using KKT conditions.

Proof of Proposition 2. Clearly, $\Pi_{2 N}^{\prime}(21)$ has the same sign as the cubic function:

$$
\begin{aligned}
M_{9}(N)= & -a(N+1)^{3}+\left(-b K+\frac{K^{2}}{2} C_{f}\left(\theta_{1} r+\theta_{2}\right)\right)(1-\delta)(N+1) \\
& +2 K^{2}\left(\theta_{3} r^{2}+\theta_{4}\right)(1-\delta)(N \delta+1)
\end{aligned}
$$


and $\lim _{N \rightarrow-1} M_{9}>0$ and $\lim _{N \rightarrow \infty} M_{9}=-\infty$. Therefore, there is at least one solution with $N>-1$. However, it is impossible to have three solutions, because if there are three real roots, then $L_{9}^{\prime}(N)$ should have two real roots larger than -1 . The first derivative of $M_{9}(N)$ simply shows that this is impossible. As a result, the solution satisfying the first order condition is the unique maximum.

Proof of Proposition 3. Taking the first derivative of $\Pi_{2}$ with respect to $\delta$ yields:

$$
\Pi_{2 \delta}^{\prime}=\frac{N b K}{(N+1)}-\frac{K^{2} C_{f}\left(\theta_{1} r+\theta_{2}\right) N}{2(N+1)}-\frac{2 K^{2}\left(\theta_{3} r^{2}+\theta_{4}\right)(N \delta+1) N}{(N+1)^{2}}
$$

Utilizing $\Pi_{2 N}^{\prime}(21)$ we have:

$$
\Pi_{2 \delta}^{\prime}=\frac{-N(N+1)}{1-\delta}\left(\Pi_{2 N}^{\prime}+a\right)
$$

So, at $N_{2}^{*}$ where $\Pi_{2 N}^{\prime}=0$, we have $\Pi_{2 \delta}^{\prime}<0$. Therefore, $\Pi_{2}$ is a decreasing function of $\delta$ for given value of $N_{2}^{*}$, and $\left(N_{2}^{*}, 0\right)$ is the optimal solution.

Proof of Theorem 1. For the lessee, there are four best response possibilities; $i, i i, i i i$, and $i v$, as presented in Proposition 1, and for the lessor, only one possibility exists as addressed in Proposition 3. Considering these cases, there are four overall candidates for the equilibria, for which only two of them satisfy the corresponding conditions. At $\delta=0$, we have $A_{1}>0$ and $B_{1}>0$, which contradicts $C_{1}<0\left(C_{1}=N B_{1}+A_{1} \alpha_{0} r_{m}^{2}\right)$. Therefore, the corresponding conditions for cases $i i i$ and $i v$ in Proposition 1 are not satisfied, and no equilibrium exists in these two cases.

Proof of Theorem 2. To prove cases $i i i$ and $i v$, notice that substituting $K^{*}=\frac{A_{3}(N+1)}{(N \delta+1)}$ into $\Pi_{2}$ yields the following optimization problem for the lessor:

$\max _{\delta, N} \quad \alpha_{0} r^{2} \frac{A_{3}(N+1)}{(N \delta+1)}-N a-\frac{N b A_{3}(1-\delta)}{(N \delta+1)}-\frac{A_{3}^{2}(N+1) C_{f}\left(\theta_{1} r+\theta_{2}\right)}{2(N \delta+1)}-A_{3}^{2}\left(\theta_{3} r^{2}+\theta_{4}\right)$

Taking the first derivative of the above objective function with respect to $\delta$ yields $M_{1}$ in (24), which is a constant function of $\delta$. When $M_{1}>0$, we have $\delta_{s}^{*}=1$, which means PM is minimal. Due to the tedious derivation involved, we only show the case with $M_{1}>0$, and the case for $M_{1}<0$ can be dealt with in a similar manner.

For case $i$, after substituting $r_{1}^{*}$ into $\Pi_{2}$, the first derivatives of $\Pi_{2}$ with respect to $N$ and $\delta$ have the same relationship as (31). Notice that $r_{1 N}^{*^{\prime}}$, the first derivative of $r_{1}^{*}$ with respect to $N$, and $r_{1 \delta}^{*^{\prime}}$, the first derivative of $r_{1}^{*}$ with respect to $\delta$, satisfy $r_{1 \delta}^{*^{\prime}}=\frac{-N(N+1)}{(1-\delta)} r_{1 N}^{*^{\prime}}$. Therefore, for any interior optimal $N_{s}^{*}$, we have $\delta_{s}^{*}=0$. 
Proof of Proposition 4. For cases iii and $i v$ of Theorem 2, no Nash equilibrium exists. In case $i i$, the two solutions are identical. In case $i$, we compare the finite and unique values $N_{3}^{*}$ and $N_{4}^{*} . N_{3}^{*}$ is derived by substituting $r_{1}^{*}=\frac{u_{m}}{2 \alpha_{0} r_{m}}\left[\frac{2 N+1}{2(N+1)}\right]$ into $\Pi_{2 N}^{\prime}=0(21)$. This is equivalent to solving $M_{5}(N)=0$, where:

$$
M_{5}(N)=-a-\frac{b L}{(N+1)^{2}}+\frac{L^{2} C_{f}\left(\theta_{1} r_{1}^{*}+\theta_{2}\right)}{2(N+1)^{2}}+\frac{2 L^{2}\left(\theta_{3}\left(r_{1}^{*}\right)^{2}+\theta_{4}\right)}{(N+1)^{3}}
$$

$N_{4}^{*}$ is derived by substituting $r_{1}^{*}$ into $\Pi_{2}$ and setting its first derivative with respect to $N$ to zero. This is equivalent to solving $M_{6}(N)=0$, where:

$$
\begin{aligned}
M_{6}(N)=-a & -\frac{b L}{(N+1)^{2}}+\frac{L^{2} C_{f}\left(\theta_{1} r_{1}^{*}+\theta_{2}\right)}{2(N+1)^{2}}+\frac{2 L^{2}\left(\theta_{3}\left(r_{1}^{*}\right)^{2}+\theta_{4}\right)}{(N+1)^{3}} \\
+ & 2 \alpha_{0} r_{1}^{*} L E_{1}-\frac{L^{2} C_{f} \theta_{1} E_{1}}{2(N+1)}-\frac{2 L^{2} \theta_{3} r_{1}^{*} E_{1}}{(N+1)^{2}}
\end{aligned}
$$

where $E_{1}=r_{1 N}^{*^{\prime}}=\frac{u_{m}}{4 \alpha_{0} r_{m}(N+1)^{2}}>0$ is the first derivative of $r_{1}^{*}$ with respect to $N$. Observe that $M_{6}(N)-M_{5}(N)$ has the same sign as $M_{2}(N)$ in (26). Clearly, $\lim _{N \rightarrow \infty} M_{2}(N)=$ $\frac{u_{m} L}{r_{m}}>0$, and $M_{2}^{\prime}(N)=2 \alpha_{0} L r_{1 N}^{*^{\prime}}+\frac{L^{2} C_{f} \theta_{1}}{2(N+1)^{2}}+\frac{2 L^{2} \theta_{3} u_{m}(4 N+1)}{4 \alpha_{0} r_{m}(N+1)^{4}}>0$. Thus, if $M_{2}(0)=$ $u_{m} \alpha_{0}-L C_{f} \theta_{1} \alpha_{0} r_{m}-L \theta_{3} u_{m}>0$, then $M_{2}(N)>0$, and if $M_{2}(0)<0$, there exists a unique finite $N_{A}$ satisfying $M_{2}(N)=0$. In the former case $N_{4}^{*}>N_{3}^{*}$, and in the latter case if $M_{5}\left(N_{A}\right)>0$ then $N_{4}^{*}>N_{3}^{*}$, and if $M_{5}\left(N_{A}\right)<0$ then $N_{3}^{*}>N_{4}^{*}$. It should be noted that $M_{3}(N)$ in $(23)$ and $M_{4}(N)$ in (25) have the same solutions as $M_{5}(N)$ and $M_{6}(N)$, respectively.

Proof of Proposition 5. i. Since the lessee's (follower's) response to every strategy of the lessor (leader) is unique, the leader's profit will not be less than that at Nash equilibrium, i.e., $\Pi_{2}\left(\mathbf{x}_{s}^{*}\right) \geq \Pi_{2}\left(\mathbf{x}_{c}^{*}\right)$. ii. We will prove $\Pi_{1}\left(r_{1}^{*}(N), L, N, 0\right)$ is increasing in $N$. Substituting $r_{1}^{*}(N)=\frac{u_{m}}{2 \alpha_{0} r_{m}}\left[1-\frac{1}{2(N+1)}\right]$ into $\Pi_{1}$ and simplifying the equation yields $\Pi_{1}(N)=\alpha_{0} L\left(r_{1}^{*}(N)\right)^{2}$, which is an increasing function of $N$ since $r_{1 N}^{*^{\prime}}=\frac{u_{m}}{4 \alpha_{0} r_{m}(N+1)^{2}}>$ 0 .

Proof of Proposition 6. Taking the first derivative of $\Pi$ with respect to $N$ yields:

$$
\Pi_{N}^{\prime}=-a-\frac{b K(1-\delta)}{(N+1)^{2}}+\frac{K^{2}(1-\delta)}{2(N+1)^{2}}\left[\frac{u_{m} r}{r_{m} L}+C_{f}\left(\theta_{1} r+\theta_{2}\right)\right]+\frac{2 K^{2}\left(\theta_{3} r^{2}+\theta_{4}\right)(N \delta+1)(1-\delta)}{(N+1)^{3}}
$$

Observe that $\Pi_{\delta}^{\prime}$ and $\Pi_{N}^{\prime}$ satisfy $\Pi_{\delta}^{\prime}=\frac{-\left(\Pi_{N}^{\prime}+a\right)(N+1)^{3}}{K(1-\delta)}$, which shows that $\Pi$ is a decreasing function of $\delta$ when $\Pi_{N}^{\prime}=0$. As a result, we have $\delta^{*}=0$. The first order derivatives of $\Pi$ with respect to $K$ and $r, \Pi_{K}^{\prime}$ and $\Pi_{r}^{\prime}$, yield the following relationship:

$$
r \Pi_{r}^{\prime}=2 K \Pi_{K}^{\prime}+C_{f} K^{2}(N+1)\left(\theta_{1} r+2 \theta_{2}\right)+4 K^{2} \theta_{4}+2 N b(N+1) K+\frac{K^{2} u_{m} r(N+1)}{r_{m} L}
$$


which shows that $\Pi_{r}^{\prime}>0\left(\right.$ as $\left.\Pi_{K}^{\prime}>0\right)$ and $\mathbf{x}_{c}^{*}=\left(r_{m}, L, N^{*}, 0\right)$ is the total maximum solution.

Proof of Proposition 7. Substituting $\delta=0$ into (33), $\Pi_{N}^{\prime}=0$ will have the same solution as $M_{7}(N)=0$, where

$$
M_{7}(N)=-a(N+1)^{3}+\left(-b K+\frac{K^{2}}{2} C_{f}\left(\theta_{1} r+\theta_{2}\right)+\frac{K^{2} u_{m} r}{2 r_{m} L}\right)(N+1)+2 K^{2}\left(\theta_{3} r^{2}+\theta_{4}\right)
$$

Following the same manner as proof of proposition 2, one can see that there is only one real positive root.

Proof of Proposition 8. After substituting $\delta=0, \Pi_{2 N}^{\prime}=0$ in (21) has the same solution as $M_{8}(N)=0$ where:

$$
M_{8}(N)=-a(N+1)^{3}+\left(-b K+\frac{K^{2}}{2} C_{f}\left(\theta_{1} r+\theta_{2}\right)\right)(N+1)+2 K^{2}\left(\theta_{3} r^{2}+\theta_{4}\right)
$$

One can see that $\lim _{N \rightarrow-1} M_{7}=\lim _{N \rightarrow-1} M_{8}>0$ and $\lim _{N \rightarrow \infty} M_{7}=\lim _{N \rightarrow \infty} M_{8}=-\infty$, and each of the equations has one real root as proved before. Besides, it can be seen that for fixed $r$ and $K$, the two cubic functions in (34) and (35) have the same coefficients except for the second terms where the coefficient of $(N+1)$ in $(34)$ has a larger value. As a result, we have $M_{7}(N)>M_{8}(N)$, and $N^{*}>N_{2}^{*}$. Next, we prove that $N_{2}^{*}>N_{3}^{*}$. Notice that $M_{8}(N)$ is an increasing function of $r$, so substituting $r_{m}$ with $r^{*}<r_{m}$ yields $M_{8}\left(N, r_{m}\right)>M_{8}\left(N, r_{1}^{*}\right)$. As a result, we have $M_{7}\left(N, r_{m}\right)>M_{8}\left(N, r_{m}\right)>M_{8}\left(N, r_{1}^{*}\right)$, so $N_{3}^{*}<N_{2}^{*}<N^{*}$. Moreover, observe that (32) is an increasing function of $r$ under the conditions of the problem, so $N_{4}^{*}<N_{2}^{*}<N^{*}$.

Proof of Proposition 10. From Proposition 8, we see that the Nash and Stackelberg equilibria are different from the total maximum solution, so their total payoff is less than the maximum total payoff in the cooperative scheme.

Proof of Proposition 11. We need to determine the parameter $\gamma$ such that $\bar{\Pi}_{1}\left(\mathrm{x}_{c}^{*}\right)=$ $\Pi_{1}\left(\mathbf{x}_{n}^{*}\right)+\Delta \Pi / 2$. That is $\Pi_{1}\left(\mathbf{x}_{c}^{*}\right)+H\left(\mathbf{x}_{c}^{*}\right)=\Pi_{1}\left(\mathbf{x}_{n}^{*}\right)+\Delta \Pi / 2$, where $\Delta \Pi=\Pi_{1}\left(\mathbf{x}_{c}^{*}\right)+\Pi_{2}\left(\mathbf{x}_{c}^{*}\right)-$ $\Pi_{1}\left(\mathbf{x}_{n}^{*}\right)-\Pi_{2}\left(\mathbf{x}_{n}^{*}\right)$ and $H(\mathbf{x})=\gamma+\bar{\alpha}_{0} r^{2} K+\frac{\beta}{N+1}$. Solving for $\gamma$ proves the results.

Proof of Proposition 12. It can be seen by case $i$ of Theorem 1 that when $D_{1}<0$ i.e., $\alpha_{0}>\frac{u_{m}\left(2 N^{*}+1\right)}{4 r_{m}^{2}\left(N^{*}+1\right)}$, then the total maximum solution $\left(r_{m}, L\right)$ and $N^{*}$ are not the best response of lessee and lessor, respectively. Besides, it can be seen by case $i i$ that when $C_{1} \geq 0$, i.e., $\alpha_{0} \leq \frac{u_{m} N^{*}}{r_{m}^{2}\left(N^{*}+1\right)}$, and $D_{1} \geq 0$, i.e., $\alpha_{0} \leq \frac{u_{m}\left(2 N^{*}+1\right)}{4 r_{m}^{2}\left(N^{*}+1\right)}$, then $\left(r_{m}, L\right)$ is the best response of the lessee. Observe that $\frac{u_{m} N^{*}}{r_{m}^{2}\left(N^{*}+1\right)} \geq \frac{u_{m}\left(2 N^{*}+1\right)}{4 r_{m}^{2}\left(N^{*}+1\right)}$, so $\alpha_{0} \leq \frac{u_{m}\left(2 N^{*}+1\right)}{4 r_{m}^{2}\left(N^{*}+1\right)}$ is the necessary and sufficient condition for the lessee to choose the total maximum solution. So 
we introduce a transfer-payment function term as $\bar{\alpha}_{0} r^{2} K$ with $\bar{\alpha}_{0}$ satisfying the relation $\alpha_{0}-\bar{\alpha}_{0} \leq \frac{u_{m}\left(2 N^{*}+1\right)}{4 r_{m}^{2}\left(N^{*}+1\right)}$ to make $\left(r_{m}, L\right)$ the best response of the lessee. Next, we show that $\frac{L u_{m}}{2(N+1)}$ is a proper transfer function, which makes $N^{*}$ the best response of lessor. The first order partial derivatives of the lessor's payoff function and total payoff function are given in (21) and (33) respectively. A comparison shows that adding the term $\frac{K^{2} u_{m} r(1-\delta)}{2 r_{m} L(N+1)^{2}}$ to (21) makes the two functions equal, so we modify the payoff functions by $\frac{\beta}{N+1}$ with $\beta=\left.\frac{K^{2} u_{m} r(1-\delta)}{2 r_{m} L}\right|_{\mathbf{x}_{c}^{*}=\left(r_{m}, L, 0\right)}=\frac{L u_{m}}{2}$ to make the first order derivatives equal. The same proof as Proposition 2 shows that $\left(N^{*}, 0\right)$ is the unique maximum for the lessor's payoff, $\bar{\Pi}_{2}$.

Proof of Proposition 13. It can be seen by Theorem 1 that when $C_{1} \geq 0$ and $D_{1} \geq 0$, then $\left(r_{m}, L\right)$ is already the best response of the lessee, so $\bar{\alpha}_{0}=0$. With the same proof as Proposition 12, it can be seen that $\frac{L u_{m}}{2(N+1)}$ is a proper transfer function, which makes $N^{*}$ the best response of lessor. Next, we show that $\gamma \leq 0$. It can be seen by (30) that $\gamma=\frac{\Pi_{1}\left(\mathbf{x}_{\mathbf{n}}^{*}\right)-\Pi_{1}\left(\mathbf{x}_{\mathbf{c}}^{*}\right)+\Pi_{2}\left(\mathbf{x}_{\mathbf{c}}^{*}\right)-\Pi_{2}\left(\mathbf{x}_{\mathbf{n}}^{*}\right)-\frac{L u_{m}}{\left(N^{*}+1\right)}}{2}$. The sum of the first two terms is negative, since $\Pi_{1}$ is increasing in $N$, and $N^{*}>N_{n}^{*}$. The sum of the terms three and four is also negative since $N_{n}^{*}$ is the optimal solution of $\Pi_{2}$, so $\Pi_{2}\left(\mathbf{x}_{\mathbf{n}}^{*}\right)>\Pi_{2}\left(\mathbf{x}_{\mathbf{c}}^{*}\right)$. Finally, $-\frac{u_{m} L}{\left(N^{*}+1\right)}<0$, and the proof is complete. 